\title{
Functional Analytical Models for Characterizing Wholly Encapsulated Confinement Systems for Design of Geo-Structures
}

\author{
John Ngaya Mukabi \\ R\&D/Design Dept. \\ Kensetsu Kaihatsu Consulting Engineers Ltd. \\ Nairobi, Kenya
}

\begin{abstract}
Although wholly encapsulated confinement systems (WECS) typically utilizing steel mesh for gabions and polymeric/soilbag encapsulation are established technologies in terms of application for temporary structures, the theory and its employment for permanent structures has only recently been inducted. The analytical models introduced in this paper are developed on the premise that the associated scientific theories and structural/geotechnical engineering concepts are explicated and that further advances are to be made in $R \& D$ (research \& development) supported by comprehensive investigations based on rigorous laboratory and in-situ (field) testing, full-scale model testing, analytical modelling, numerical simulation as well as monitoring and evaluation. Examples of parameters generated using the proposed analytical models that can be adopted for developing design catalogues for structural foundations and full-depth pavements structures for unpaved and paved (sealed) LVRs (low volume roads) are provided. Possible functions and attested applications are also introduced.
\end{abstract}

Keywords - Encapsulated confinement system, WECS, analytical models, design, geo-structures, fill geomaterial.

\section{INTRODUCTION}

\section{A. Background for developing analytical models}

For a long time, wholly encapsulated confinement systems (WECS) such as soilbags (do-nou in Japanese) have been used to prevent flow of soils from floodwaters and building temporary structures in cases of emergency. However, until as recent as 1991 no application of soilbags had been made for building permanent structures $\{[1],[2],[3]\}$. This might have been due to lack of knowledge about the mechanical behaviour of soilbags and the deterioration thereof after an extended period of exposure to sunlight, especially the polyethylene made soilbags which are very sensitive to ultraviolet rays (sunlight). Findings of research trials carried out in Kenya inspired the development of the application of the WECS earth reinforcement technology for road foundation. In Japan, for example, this reinforcing method has been successfully applied in such cases as for the reinforcement of ballast foundation under railway sleepers, reinforcement for soft building foundations and the construction of embankments and retaining walls [3]. In these applications, attention was paid to protect soilbags from sunlight by either embedding them in the ground or using thin facing concrete slabs/columns.

Essentially, external loading on the WECS enables mobilization of the tensile strength of the fabric of the bag, which enhances the bearing capacity of the soil by several times depending on the tensile strength/stiffness of the soilbag fabric and properties of the fill geomaterials. Experimental testing and investigations have indicated the possible increase of the bearing capacity (load) of a soft building foundation by as high as 5-10 times [2]. In this Study, the WECS considered is predominantly a system of geomaterials encapsulated within varying types of polymeric bags.

The analytical models developed in this Study can be applied in a wide range of encapsulated units of geostructures including foundations, pavements, embankments, reinforced earth retaining walls, among others.

\section{B. Theoretical and conceptual considerations}

As depicted in Figures 1 5, when WECS are progressively subjected to external loading, varying modes of encapsulation, cellular and laminated confinement/reinforcement mechanisms become prevalent depending on the stage and/or conditions of loading. The considerations in this respect include: (a) fully encapsulated; (b) partially encapsulated; (c) cellular confinement; (d) discrete planar frictional/bonding confinement/resistance; and (e) laminated planar frictional/bonding confinement/resistance. As demonstrated in these figures, the number of nodes and encapsulating planes determine the degree of influence of the prevalent mechanisms on the magnitude of the tensile resistance and strength/stiffness developed.

A comparison of Figures 1 and 2 explicitly shows the significantly enhanced efficacy resulting from the mechanisms of a fully encapsulated confinement system. The rupture of the loading plane is simulated in consideration of unpaved roads, whereby sections of the gravel wearing course are totally depleted resulting in exposure of the do-nou (soilbags) to tyre traction stresses and sunlight which end up causing the rupture of the soilbag. Theoretically, the fully encapsulated confinement system can be considered in terms of 3D planes, whilst the partially encapsulated confinement system consists of 2D planes. 


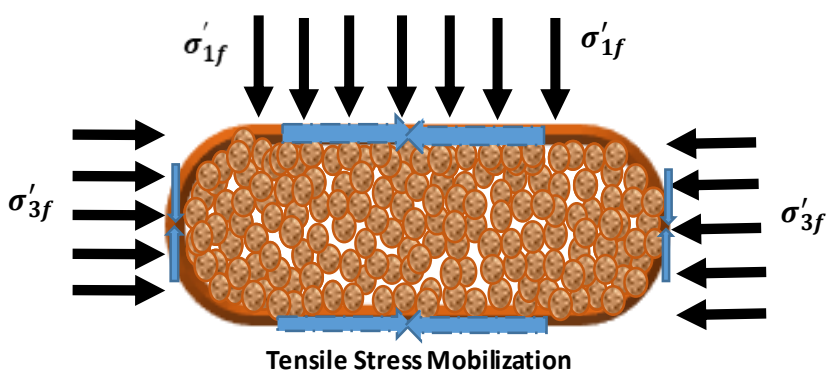

Fig. 1. Fully encapsulated confinement system - tensile stresses highly mobilized due to external loading (Figure 6): Soil particles are densely packed resulting in reduced voids ratio, enhanced confining stress, density, shearing resistance, bearing strength/capacity and apparent cohesion.

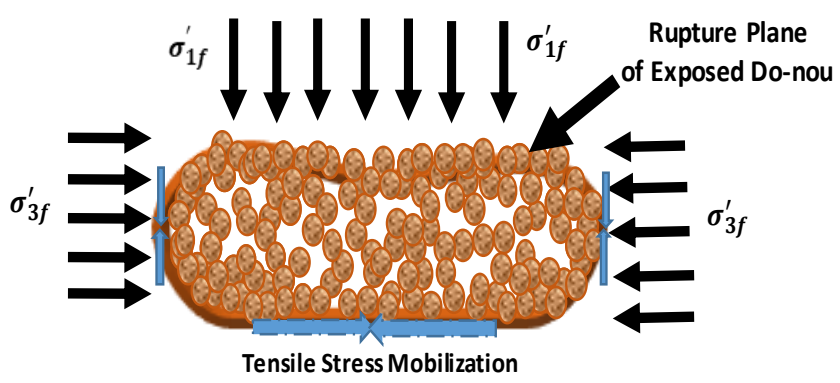

Fig. 2. Partially encapsulated confinement system - tensile stresses partially mobilized due to external loading (Figure 7): Increase in voids ratio resulting in decrease in confining stress, density, shearing resistance, bearing

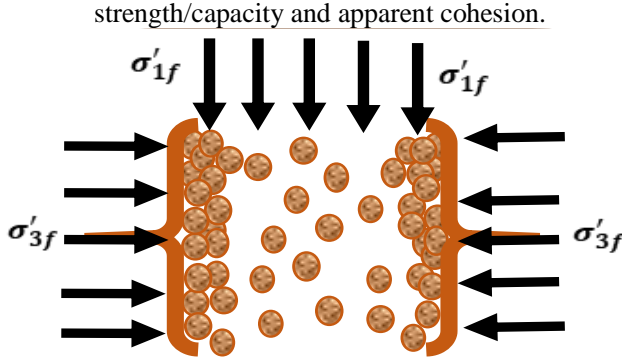

Fig. 3. Cellular confinement: Tensile stress mobilization concentrated in the along the lateral 2D planes (Figure 8).

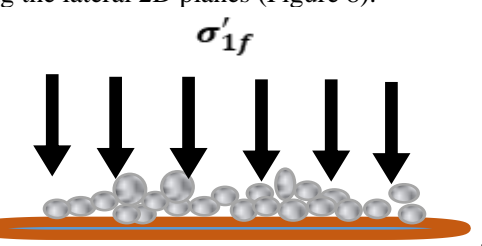

Fig. 4. Discrete planar frictional/bonding confinement/resistance: Surface acting as a geotextile

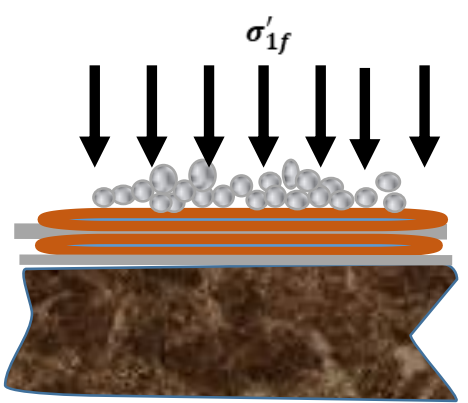

Fig. 5. Laminated planar frictional/bonding confinement/resistance: Surface acting as a laminated geotextile with enhanced tensile properties.
The following considerations define the modes presented in Figures $1 \sim 5$. The examples are based on results reported in [4].

1. Fully encapsulated (Fig. 1): Entails that all the three dimensional (3D) planes are triggered into the action of total confinement acting as a composite slab generating tensile stresses in all 3D planes to provide resistance to the external loading (Figure 6). This would occur during the advanced stages of pre-failure and at failure when the tensile stresses are fully mobilized. Note that full encapsulation involves all the subsequent mechanisms explained from Figures $2 \sim 5$.

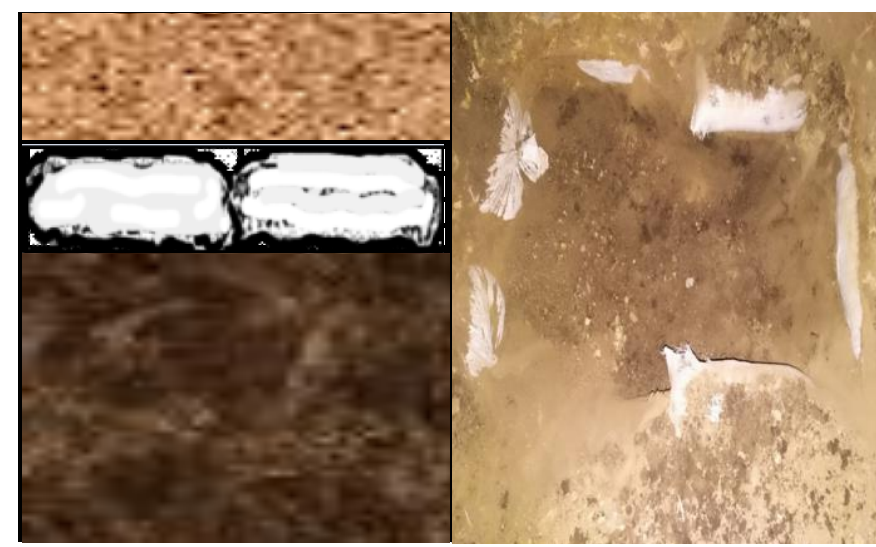

Fig. 6. Cross-sectional perspectives of single layer embedded do-nou (soilbags): (a) schematic of log profile; and (b) trial pit excavated during performance evaluation of the Kirima Kianoe Road in Nakuru County (MTRD Evaluation Report No. 1314: April, 2018).

2. Partially encapsulated (Fig. 2): This phenomenon would occur after total loss of the overlaying gravel wearing course when the upper plane (external loading stress recipient plane) of the soilbags is exposed as shown in Figure 7. In this case partial encapsulated confinement occurs due to the two lateral planes and the bottom horizontal plane in direct contact with the pavement foundation or subgrade.

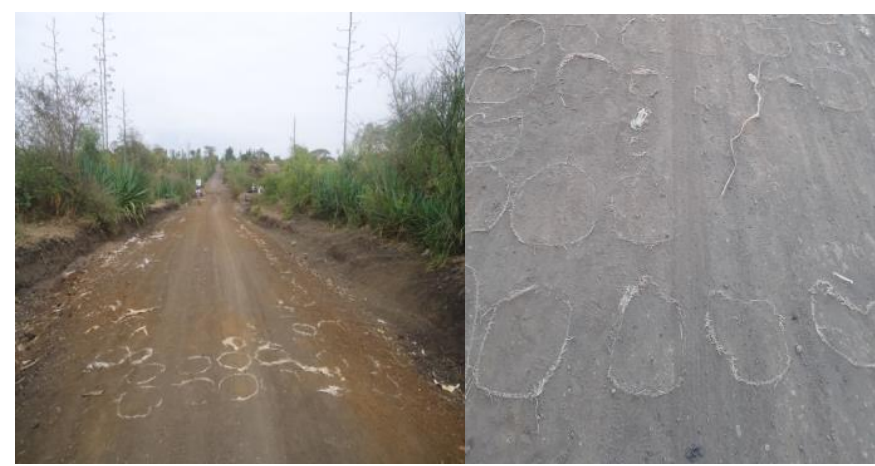

Fig. 7. Exposed do-nou (soilbags) resulting from total loss of overlaying gravel wearing course investigated during performance evaluation of the trial/improved sections in Embu County, Kenya (MTRD Evaluation Report No. 1314: April, 2018)

3. Cellular confinement (Fig. 3): The phenomenon of cellular confinement systems is well illuminated by geocells in general and the loading and failure modes [5], geocell confinement geometry (Figure 8b) and the lateral confinement mechanisms depicted in Figure 8a. In this case, 
as can be derived from the LHS depiction in Figure 8, the geocell triggers tensile stress mobilization as a result of lateral confinement and stabilizes the subgrade reaction against external loading. With reference to WECS, the bottom, if intact (not depleted) would provide additional tensile resistance and further stabilization to the subgrade reaction. This would occur after total depletion of the overlaying gravel wearing course when the upper plane (external loading stress recipient plane) of the soilbags is exposed as shown in Figure 7 above.

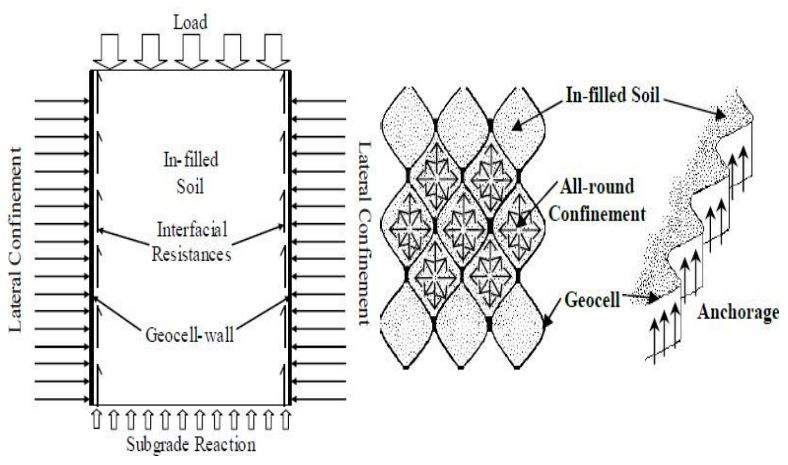

Fig. 8. Cellular confinement: a) tensile stress mobilization concentrated in the along the lateral 2D planes; and b) reinforcing geometry and mechanisms.

4. Discrete planar frictional/bonding confinement/resistance (Fig. 4): This mechanism would be analogous to the one exhibited by a geotextile embedded within a pavement layer to act as a reinforcing element. The stabilization/reinforcement of the layer within which it is embedded results from the friction and bonding of the geotextile with the soil particles within the particular layer generating a zone of influence of specific interface thickness and characteristics.

In consideration of the tensile strength/stiffness development of the WECS, the frictional/bonding confinement/resistance actually occurs in the initial stage of loading prior to the prevalence of full encapsulation mechanisms (vicinity of the loading surface in Figure 9b on the RHS). This action would be predominant within the elastic and elasto-plastic zones of the kinematic hardening framework.
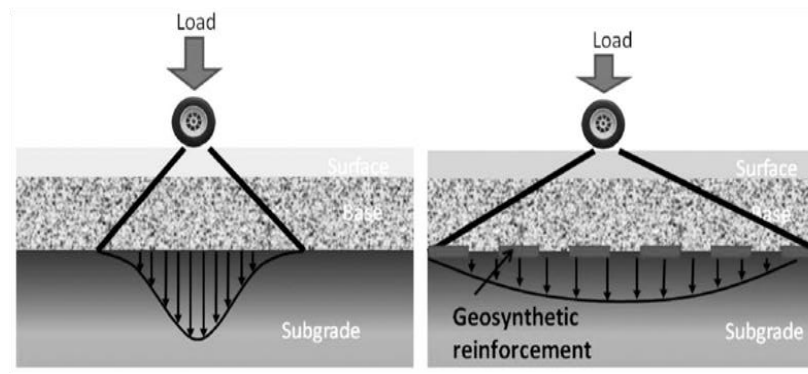

Fig. 9. Transformation of shear surface resulting in reinforcement of subgrade due to inclusion of frictional geotextile.

5. Laminated planar frictional confinement/resistance (Fig. 5): Figure 10, which depicts cross-sectional perspectives of a log profile and trial pit, is an example of a multi-layer structural application of WECS soilbags (do-nou).

$\mathrm{t}$ can be observed from Figure 10a that a laminated interface exists between the first and second layers of the
WECS. As validated in sub-Sections II-E. and II-F., the tensile strength increases in proportion to the number of layers and lamination interfaces, respectively. Accordingly, therefore, it is essential that these characteristics are taken into account during the design and structural performance evaluation WECS geostructures

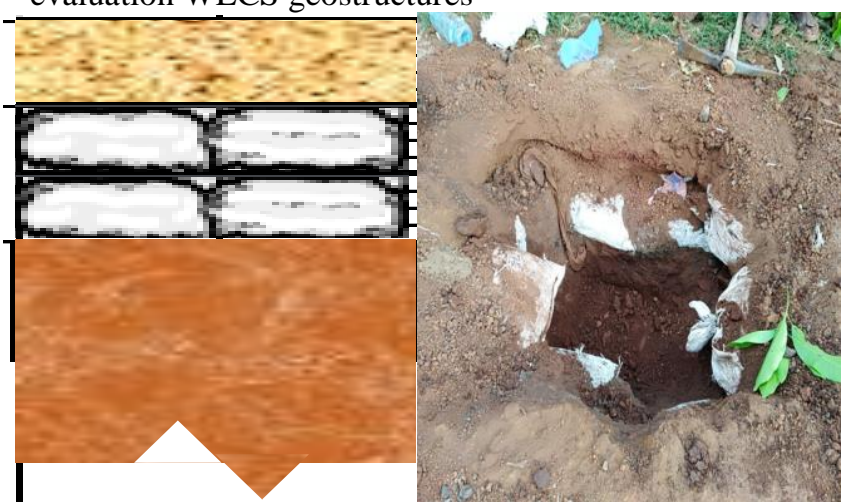

Fig. 10. Cross-sectional perspectives of double layer embedded do-nou (soilbags): (a) schematic of log profile; and (b) trial pit excavated during performance evaluation of the Kerugoya $\sim$ Kamondo Road in Kirinyaga County (MTRD Evaluation Report No. 1314: April, 2018).

\section{Fundamental considerations of design approach}

The fundamental considerations for choice of the appropriate design for WECS technology are mainly influenced by overlay thickness of layer covering the soilbags and type of surfacing, details of which are discussed in Section II and Section IV.

\section{FUNDAMENTAL STRUCTURAL DESIGN PRINCIPLES}

\section{A. Criteria for development of structural design principles}

In deriving the structural design principles, consideration of the fundamental design aspects including philosophy/criteria, climatic and environmental conditions, mode of interpretation/evaluation of traffic/load factors, materials characterization and classification, analyses of vital mechanisms required for appropriate use of WECS soilbags and the effective evaluation thereof for purposes of advancing this technology were made accordingly. Methods of evaluation and optimization of the accruing benefits are also included as integral considerations.

In particular, the following considerations have been made: i) the reinforcement/improvement/stabilization mechanisms resulting from the use of the WECS technology; ii) strength and stiffness development soil mechanics theories and geotechnical engineering concepts; iii) appropriate methods of evaluating the developed bearing capacity; iv) influence of the size and shape of the WECS (soilbags); v) encapsulation characteristics and contribution to deformation resistance; vi) performance evaluation of the possible functions associated with the use of do-nou; vii) the fundamental design criteria including loading characteristics and stress-strain behavior, failure criterion for the bags, composite WECS, WECS foundation and natural/existing subgrade, area coverage ratio, relevant and appropriate partial factors and design life; viii) evaluation of material properties and the appropriate selection criteria of the reinforcing elements and fill geomaterials; ix) characterization of encapsulated fill geomaterials; $\mathrm{x}$ ) criteria for evaluation of applicability and benefits; xi) criteria for 
selected pavement structural configurations provided within the charts in Chapter 5 of this DG-4; and xii) criteria for the developed design catalogues that are presented in [6].

\section{B. Strength and stiffness development mechanisms}

Based on the theoretical and conceptual considerations elucidated in the preceding Section I, strength and stiffness development mechanisms prevail when soilbags are externally loaded and tensile stresses are mobilized as a result. This advantage is used to reinforce various geo-structures including soft foundations for pavements and buildings, embankments and retaining walls. In general, as shown in Figure 1, use of soilbags becomes effective when they are subjected to vertical forces from the upper structures. Figure 1 shows a soilbag subjected to principal stresses, at failure; $\sigma_{1 f}$ and $\sigma_{3 f}$ from a two dimensional perspective. Considering that the fill material within the soilbag is frictional and granular, to an appreciable extent, at constant volume condition and under the actions of $\sigma_{1 f}$ and $\sigma_{3 f}$, the total perimeter of the bag would usually increase as a result of reduction in the height (thickness) due to the compaction/consolidation/compression effects on the fill geomaterial.

Subsequently, the bag compacts vertically and a tensile force $\mathrm{T}$ is developed along the $3 \mathrm{D}$ planes of the soilbag fabric. The dilatancy occurring inside the bag helps to develop high tensile forces. The tensile force $\mathrm{T}$ produces additional stresses that act on the particles inside the soilbag whose vertical and horizontal (lateral) components are expressed as defined in Equations (1) and (2), respectively.

and,

$$
\sigma_{01}^{\prime}=\frac{2 T}{(B \times L)}
$$

$$
\sigma_{03}^{\prime}=\frac{2 T}{(H \times L)}
$$

where $B$ and $H$ are the width and height of the soilbag, respectively and $L$ is the length which is considered to be unity $(L=1)$.

Thus, as illustrated in Figure 1, the stresses acting on the particles are the combination of external stresses and stress caused by the tensile force (T) of the Do-nou fabric. At failure, the major effective principal stress $\sigma_{1 f}^{\prime}$ can be calculated from Equation (3):

$$
\sigma_{1 f}^{\prime}=\left(\sigma_{3 f}^{\prime}+\frac{2 T}{H}\right) K_{p}-\frac{2 T}{B}
$$

On the other hand, based on soil mechanics principles for cohesive-frictional geomaterial $\left(c-\phi_{f}^{\prime}\right)$ in general and pertinent stress ratio concepts in particular, $\sigma_{1 f}^{\prime}$ can be expressed in terms of strength @ failure as:

$$
\sigma_{1 f}^{\prime}=\sigma_{3 f}^{\prime} K_{p}+2 c_{R} \sqrt{K_{p}}
$$

where, $c_{R}$ is the apparent cohesion resulting from the tensile stresses acting on and within the soilbag, Now, taking the RHS term in Equation (4), substituting $\sigma_{1 f}^{\prime}$ in Equation (3), rearranging the terms and solving for $c_{R}$ yields:

$$
\begin{array}{r}
c_{R}=\frac{T}{B \sqrt{K_{p}}}\left(\frac{B}{H} K_{p}-1\right) \\
K_{p}=\frac{1+\sin \left(\phi_{f}^{\prime}\right)}{1-\sin \left(\phi_{f}^{\prime}\right)}
\end{array}
$$

From Figure 1, it is inferred that the soilbag can be considered to be under triaxial conditions. In order to better simulate these conditions therefore, it is advisable that the angle of internal friction/shearing resistance, $\phi_{f}^{\prime}$, which is a significantly influential parameter, be appropriately determined from triaxial tests. However, given the complexity and the fact that it is scarcely available, the following model and Table I can be employed in converting the $\phi_{f}^{\prime}$ values determined from direct shear testing to equivalent values that would be obtained from triaxial tests.

$$
\phi_{f, t x}^{\prime}=\exp \left[0.72057 \ln \left(6.3196 \phi_{f, d s}^{\prime 0.9019}\right)\right]
$$

Table I provides a summary of useful values for $\phi_{f}^{\prime}$ within the range that is typically encountered.

TABLE I. CONVERSION OF $\boldsymbol{\phi}_{f}^{\prime}$ VALUES FROM DIRECT SHEAR TESTS TO THE TRIAXIAL EQUIVALENTS.

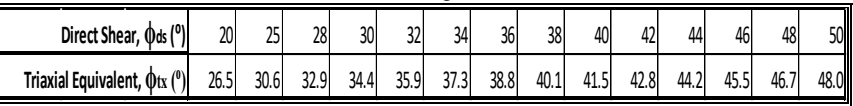

On the other hand, Equation (5) can be verified by considering the model adopted in defining and quantifying the apparent cohesion that prevails due to soilbags (geotextile) reinforcement as is expressed in Equation (8).

$$
c_{R}=\Delta \sigma_{3 R}^{\prime} \sqrt{K_{p}}
$$

where, $\Delta \sigma_{3 R}^{\prime}$ is the apparent increase in confining stress as a result of WECS soilbags reinforcement, which is defined in Equation (9) with slight modification to account for the fully encapsulated confinement effects as exhibited by the WEC system.

$$
\Delta \sigma_{3 R}^{\prime}=0.7^{\left(H / 6 d_{\max }\right)} \frac{2 T}{H}
$$

Substituting for $\Delta \sigma_{3 R}^{\prime}$ in Equation (8) yields:

$$
c_{R}=\left[0.7^{\left(H / 6 d_{\max }\right)} \frac{2 T}{H}\right] \sqrt{K_{p}}
$$

Note that model Equations (9) and (10) account for the effects of intrinsic mechanical stability (gradation) of the fill geomaterial in terms of the average maximum particle size whose typical representative value for gravelly material is considered to be between: $d_{\max }=8 \mathrm{~mm}(0.008 \mathrm{~m})$ and $d_{\text {max }}=10 \mathrm{~mm}(0.01 \mathrm{~m})$ based on the results from [4].

Validation is achieved by comparing the apparent cohesion values computed using Equations (5) and (10) for varying quality of fill geomaterial defined in terms of the angle of internal friction/shearing resistance and ultimate tensile strengths for the two typical polyethylene that can be available in Kenya. The comparison is made in Table II and graphically demonstrated in Figure 11.

Based on the virtually perfect superimposition of the characteristic curves depicted in Figure 11, it can be derived that Equation (5) is very well validated. Consequently, it is also verified that values for the apparent cohesion generated from either Equation (5) or Equation (10) that are summarized in Table II are applicable in design. The models shall be adopted directly in cases where there are changes in soilbag dimensions and/or maximum particle size of the fill geomaterial is significantly greater than $10 \mathrm{~mm}$. However, it should be noted that, for optimal results using the WECS soilbag technology, the UBL upper boundary limit of the maximum particle size is: $d_{\text {max }}=20 \mathrm{~mm}(0.02 \mathrm{~m})$ 
TABLE II. SUMMARY OF APPARENT COHESION VALUES APPLICABLE IN DESIGN.

\begin{tabular}{|c|c|c|c|c|c|c|c|}
\hline \multicolumn{2}{|c|}{ Type of Fabric (Material) } & \multicolumn{2}{|c|}{ Polyethelene } & \multicolumn{2}{|c|}{ Polypropylene } & \multicolumn{2}{|c|}{ Polyester } \\
\hline & Tult. (kN/m) & \multicolumn{2}{|c|}{6.6} & \multicolumn{2}{|c|}{11.2} & \multicolumn{2}{|c|}{20} \\
\hline \multicolumn{2}{|r|}{ Country of Origin } & \multicolumn{2}{|c|}{ China } & \multicolumn{2}{|c|}{ Kenya } & \multicolumn{2}{|c|}{ Japan } \\
\hline \multirow[t]{2}{*}{$\begin{array}{c}\text { AlF/ASR, } \\
\phi_{t x}\end{array}$} & $\begin{array}{l}\text { Coefficient of } \\
\text { Passive Earth }\end{array}$ & \multicolumn{6}{|c|}{ Apparent Cohesion, $\mathrm{C}_{\mathrm{R}}(\mathrm{kPa})$} \\
\hline & & Eq. (5) & Eq. (10) & Eq. (5) & Eq. (10) & Eq. (5) & Eq. (10) \\
\hline 20 & 2.040 & 83 & 90 & 140 & 152 & 251 & 27. \\
\hline 25 & 2.464 & 93 & 99 & 158 & 167 & 282 & 295 \\
\hline 28 & 2.770 & 100 & 104 & 170 & 177 & 303 & 317 \\
\hline 30 & 3.000 & 105 & 109 & 178 & 185 & 318 & 330 \\
\hline 32 & 3.255 & 110 & 113 & 187 & 192 & 333 & 343 \\
\hline 34 & 3.537 & 115 & 118 & 196 & 200 & 350 & 358 \\
\hline 36 & 3.852 & 121 & 123 & 206 & 209 & 367 & 373 \\
\hline 38 & 4.204 & 127 & 129 & 216 & 218 & 386 & 390 \\
\hline 40 & 4.599 & 134 & 135 & 227 & 228 & 406 & 408 \\
\hline 42 & 5.045 & 141 & 141 & 239 & 239 & 427 & 427 \\
\hline 44 & 5.550 & 148 & 148 & 252 & 251 & 450 & 448 \\
\hline 46 & 6.126 & 157 & 155 & 266 & 264 & 475 & 471 \\
\hline 48 & 6.786 & 166 & 164 & 281 & 278 & 502 & 496 \\
\hline 50 & 7.549 & 175 & 173 & 298 & 293 & 531 & 523 \\
\hline
\end{tabular}

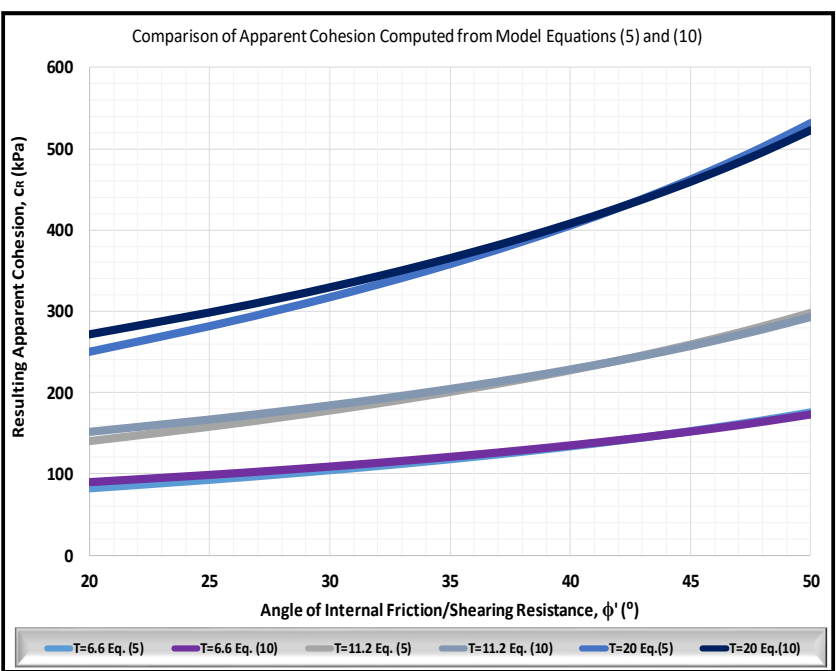

Fig. 11. Comparison of apparent cohesion values determined from analytical model Equations 5 and 10.

Note that the values summarized in Table II are for areas with flat terrain. In other words, the load is vertical without inclination $(\delta=0)$, where $\delta$ is the angle of the slope. For sloppy areas these values are corrected using Equation (11).

$$
c_{R}(\delta)= \begin{cases}c_{R}\left(\delta=0^{\circ}\right) \times \cos (2 \delta), & \left(0^{\circ} \leq \delta \leq 45^{\circ}\right) \\ 0, & \left(45^{\circ} \leq \delta \leq 90^{\circ}\right)\end{cases}
$$

\section{Analytical evaluation of strength and stiffness properties}

Key Standard methods of evaluating the bearing capacity of WECS do-nou include experimental testing and mathematical models. Standard methods of testing that have been adopted to evaluate the bearing capacity include the UCS (Unconfined Compressive Strength) in the laboratory and the PL/BT (Plate Loading/ Bearing Test).

1) Guidance on range of bearing capacity and stiffness based on unconfined compression strength (UCS) tests.

Laboratory tests, detailed in [4] and [7], carried out on WECS show strength improvement of up to ten times that of the unreinforced soil. On the other hand, Table III presents a summary of ranges of bearing capacity values determined from unconfined compression tests that can be applicable in the evaluation of bearing capacity of discrete WECS soilbags. It is important to note that the bearing capacity of the soilbags is mainly a function of the ultimate tensile strength as well as the apparent lateral/confining stress and apparent cohesion, which increase due to the mobilized tensile stresses as a result of the fully encapsulated confinement effect.

TABLE III. APPLICABLE RANGE FOR BEARING CAPACITY

\begin{tabular}{|c|c|c|c|c|c|}
\hline \multirow[t]{2}{*}{$\mathbf{S} / \mathbf{N}$} & \multirow{2}{*}{$\begin{array}{c}\text { Type of } \\
\text { Fabric } \\
\text { Material }\end{array}$} & \multirow{2}{*}{$\begin{array}{c}\text { Ultimate } \\
\text { Tensile } \\
\text { Strength } \\
(\mathbf{k N} / \mathbf{m})\end{array}$} & \multicolumn{2}{|c|}{$\begin{array}{l}\text { Range of Load/ } \\
\text { Strength/Stiffness }\end{array}$} & \multirow{2}{*}{$\begin{array}{c}\text { Fill } \\
\text { Geomateri } \\
\text { als }\end{array}$} \\
\hline & & & $\begin{array}{l}\text { Load } \\
@ \\
\text { Failure } \\
(\mathrm{kN})\end{array}$ & $\begin{array}{c}\text { Bearing } \\
\text { Strength } \\
\text { (Stiffnes } \\
\text { @ } \\
\text { Failure } \\
\text { (MPa) }\end{array}$ & \\
\hline 1. & $\begin{array}{l}\text { Polyethylene } \\
\text { (PE) }\end{array}$ & 12 & $\begin{array}{l}230- \\
280\end{array}$ & $\begin{array}{l}1.44 \\
1.75 \\
(390 \\
625)\end{array}$ & $\begin{array}{c}\text { Crushed } \\
\text { Stone/Sand }\end{array}$ \\
\hline 2. & $\begin{array}{l}\text { Polyester } \\
\text { (PET) }\end{array}$ & 20 & $\begin{array}{l}540- \\
640\end{array}$ & $\begin{array}{l}3.375 \\
4.0 \\
(4350 \\
7450)\end{array}$ & $\begin{array}{c}\text { Crushed } \\
\text { Stone/Sand }\end{array}$ \\
\hline 3. & $\begin{array}{l}\text { Polypropylene } \\
\text { (PP) }\end{array}$ & 6.6 & $\begin{array}{l}250- \\
300\end{array}$ & $\begin{array}{l}1.56 \\
1.875 \\
(470 \\
750)\end{array}$ & $\begin{array}{c}\text { Lateritic } \\
\text { Gravel }\end{array}$ \\
\hline
\end{tabular}

2) Mathematical models for estimating bearing capacity based on UCS testing

Useful mathematical/analytical models for estimating the bearing strength/capacity of WECS soilbags are introduced. Under unconfined compression conditions, the minor principal stress, $\sigma_{3}$ does not take effect. In other words, $\sigma_{3}=0$ Essentially therefore, considering $\sigma_{3}=0$ and substituting the same in Equation (3) and rearranging the terms, the major principal stress, $\sigma_{1 f}^{\prime}$ can be predicted from Equation (12).

$$
\sigma_{1 f}^{\prime}=\left(\frac{2 T}{B}\right)\left[\left(\frac{B}{H}\right) K_{p}-1\right]
$$

The load at failure can be predicted by introducing the planar dimensions comprising of the width, $B$ and the length, $L$ of the soilbag as is expressed in Equation (13).

$$
P_{L}=\left(\frac{2 T}{B}\right)\left[\left(\frac{B}{H}\right) K_{p}-1\right] \times B \times L
$$

Essentially therefore, considering $\sigma_{3 f}^{\prime}=0$ and substituting the same in Equation (3) yields:

$$
\sigma_{1 f}^{\prime}=\frac{2 T}{H} K_{p}-\frac{2 T}{B}
$$

Multiplying the RHS of Equation (14) by $B / H$ to derive common terms and rearranging the terms enables the major principal stress, $\sigma_{1 f}^{\prime}$ to be predicted from Equation (15).

$$
\sigma_{1 f}^{\prime}=\left(\frac{2 T}{B}\right)\left[\left(\frac{B}{H}\right) K_{p}-1\right]
$$

The load at failure can then be predicted by introducing the planar dimensions comprising of the width, $B$ and the length, $L$ of the soilbag as is expressed in Equation (16).

$$
P_{L}=\left(\frac{2 T}{B}\right)\left[\left(\frac{B}{H}\right) K_{p}-1\right] \times B \times L
$$

Considering that the post-compaction dimensions of the WECS do-nou to be the same in all cases of application, it can be derived that $B=L$ and $B=4 H$. Taking advantage of these relations, Equations (15) and (16) can be derivatively 
expressed to be dimensionally dependent on only the thickness (height), $H$ of the WECS soilbag by substituting for $B$ in Equations (15) and (16), Equations 17 and 18 are obtained.

$$
\begin{array}{r}
\sigma_{1 f}^{\prime}=\left(\frac{2 T}{4 H}\right)\left[\left(\frac{4 H}{H}\right) K_{p}-1\right] \\
\sigma_{1 f}^{\prime}=\left(\frac{2 T}{4 H}\right)\left[\left(\frac{4 H}{H}\right) K_{p}-1\right] \times 4 H^{2}
\end{array}
$$

The equations hence take the simplified form defined in model Equations (19) and (20).

$$
\sigma_{1 f}^{\prime}=\left(\frac{T}{2 H}\right)\left[4 K_{p}-1\right]
$$

The load at failure can be predicted by introducing the planar dimensions of the soilbag as is expressed in Equation (20).

$$
P_{L}=\left(\frac{T}{2 H}\right)\left[4 K_{p}-1\right] \times 16 H^{2}
$$

Note that these prediction equations are significantly important mainly due to the following advantages/facilitation.

a. Enable estimation of the stresses and loads at failure which can be adopted in design in the absence of testing facilities. This is quite simply possible based on the magnitude of the ultimate tensile strength, $T$ of the soilbag material and the angle of internal friction/shearing resistance, $\phi_{f}^{\prime}$ of the fill geomaterials, parameters which are knowns or can be derived from simple tests and/or models.

b. Enable design of appropriate loading capacities for the load components for UCS laboratory tests.

c. Stiffness (elastic modulus) can be predicted by using these results and small strain sophisticated predictive models.

d. The parameters can be adopted for the design of preconstruction trial sections, construction QCA and structural performance evaluation.

It is essential, however, to note that Equations (14) (20) do not take the deformation (change in the dimensions) of the WECS soilbags, which undergoes progressive loading to failure, into consideration. This influences the confidence level of the predicted parameters. In order to circumvent this problem, a deformation parameter, which is a function of the ultimate tensile strength, $T$ of the soilbag material, the angle of internal friction/shearing resistance, $\phi_{f}^{\prime}$ of the fill geomaterials and the soilbag initial thickness, $H$, is introduced. The deformation parameter, $\Phi_{\delta}$ can be computed from Equation (21) and introduced as a multiplier in Equations (14) (20).

$$
\Phi_{\delta}=0.04251 \exp \left(0.0321 \phi_{r s f}^{\prime}\right) T_{u l t}
$$

On the other hand, where the deformation, $\delta$ can be estimated, then Equations (22) can be adopted based on the concept of constant volume associated with fully encapsulated confinement systems.

$$
\sigma_{1 f}^{\prime}=\left(\frac{T}{2(H-\delta)}\right)\left[4 K_{p}-1\right]
$$

The load at failure can be predicted by introducing the planar dimensions of the soilbag as is expressed in Equation (23).

$$
P_{L}=\left(\frac{T}{2(H-\delta)}\right)\left[4 K_{p}-1\right] \times 16(H+\delta)^{2}
$$

Equations (22) and (23) are employed in generating Table IV that is applicable for predicting bearing capacities and loads, for testing, design, construction QCA and structural performance evaluation. In this table, the deformation at failure is accounted for as: $\delta=7.5 \mathrm{~mm}(0.0075 \mathrm{~m})$, which is

\begin{tabular}{|c|c|c|c|c|}
\hline \multicolumn{2}{|r|}{ Type of Fabric } & $\mathrm{PE}$ & PP & PET \\
\hline \multicolumn{2}{|r|}{ Tult. (kN/m) } & 6.6 & 11.2 & 20 \\
\hline \multicolumn{2}{|c|}{ Country of Origin } & China & Kenya & Japan \\
\hline $\begin{array}{c}\text { AIF/ASR, } \\
\phi_{t x}\end{array}$ & $\begin{array}{l}\text { Coefficient of } \\
\text { Passive Earth } \\
\text { Pressure, Kp }\end{array}$ & \multicolumn{3}{|c|}{ Bearing Capacity, $\sigma_{1 f}(\mathrm{kPa})$} \\
\hline 20 & 2.040 & 255 & 433 & 774 \\
\hline 25 & 2.464 & 316 & 536 & 957 \\
\hline 28 & 2.770 & 360 & 610 & 1090 \\
\hline 30 & 3.000 & 392 & 666 & 1189 \\
\hline 32 & 3.255 & 429 & 728 & 1299 \\
\hline 34 & 3.537 & 469 & 796 & 1421 \\
\hline 36 & 3.852 & 514 & 872 & 1558 \\
\hline 38 & 4.204 & 564 & 957 & 1710 \\
\hline 40 & 4.599 & 621 & 1053 & 1881 \\
\hline 42 & 5.045 & 684 & 1161 & 2073 \\
\hline 44 & 5.550 & 756 & 1283 & 2292 \\
\hline 46 & 6.126 & 839 & 1423 & 2541 \\
\hline 48 & 6.786 & 933 & 1583 & 2827 \\
\hline 50 & 7.549 & 1042 & 1767 & 3156 \\
\hline
\end{tabular}

an average value determined from literature and in consideration of a yield strain of $\varepsilon_{a}=15 \%$ of the WECS donou (soilbag) fabric (refer to Table VII).

TABLE IV. PREDICTED PARAMETRIC VALUES APPLICABLE FOR TESTING, DESIGN, CONSTRUCTION QCA AND STRUCTURAL PERFORMANCE FOR BEARING CAPACITIES @ FAILURE.

Notes: PE-Polyethylene; PP-Polypropylene; PET-Polyester.

The predicted values show extremely good compatibility with experimental test results reported in international publications (deviation/difference within $\pm 10 \%$ ). Application of these values is therefore recommended. Note that the model defined in Equation (21) should be adopted in cases where the soilbag fill geomaterial exhibits high shearing resistance.
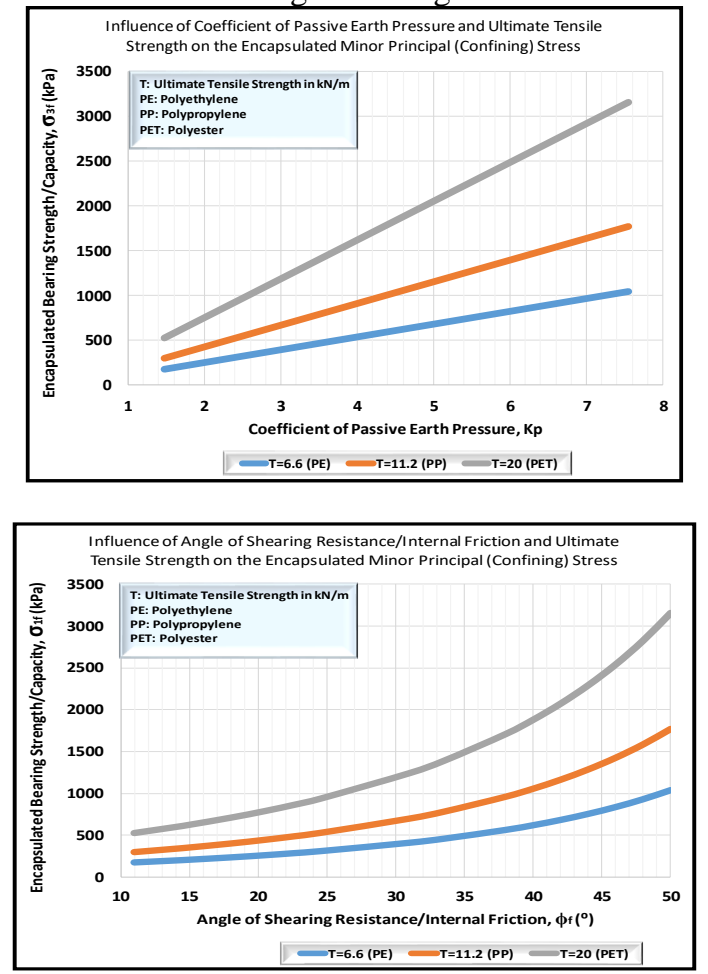

Fig. 12. Effects of ultimate tensile strength of soilbag fabric on encapsulated bearing capacity with varying: a) coefficient of passive earth pressure; and, b) angle of shearing resistance. 
Thus Another integral factor to consider is that, as a result of the tensile stresses mobilized within the soilbag apparent intrinsic confining stress, $\Delta \sigma_{3 R}^{\prime}$ and apparent intrinsic cohesion, $c_{R}$ will be progressively prevalent to failure. $\Delta \sigma_{3 R}^{\prime}$ can be derived from Equation (3) as follows.

$$
\begin{gathered}
\Delta \sigma_{3 R}^{\prime} K_{p}=\sigma_{1 f}^{\prime}-\frac{2 T}{H} K_{p}+\frac{2 T}{B} \\
\Delta \sigma_{3 R}^{\prime}=\frac{1}{K_{p}}\left(\sigma_{1 f}^{\prime}-\frac{2 T}{H} K_{p}+\frac{2 T}{B}\right)
\end{gathered}
$$

Substituting for $\sigma_{1 f}^{\prime}$ in Equation (25) from the expression in Equation (22) yields Equation (26).

$$
\Delta \sigma_{3 R}^{\prime}=\frac{1}{K_{p}}\left\{\left[\left(\frac{T}{2(H-\delta)}\right)\left(4 K_{p}-1\right)\right]-\frac{2 T}{H} K_{p}+\frac{2 T}{B}\right\}
$$

Equation (26) can be rewritten as:

$$
\Delta \sigma_{3 R}^{\prime}=\frac{T}{2 H K_{p}}\left[\left(\frac{\left(4 K_{p}-1\right) H}{(H-\delta)}\right)-\left(4 K_{p}-1\right)\right]
$$

and further rearranged to:

$$
\Delta \sigma_{3 R}^{\prime}=\frac{T\left(4 K_{p}-1\right)}{2 H K_{p}(H-\delta)}[H-(H-\delta)]
$$

Consequently, $\Delta \sigma_{3 R}^{\prime}$ can be quantitatively evaluated from Equation (29).

$$
\Delta \sigma_{3 R}^{\prime}=\frac{T\left(4 K_{p}-1\right)}{2 H K_{p}(H-\delta)} \delta
$$
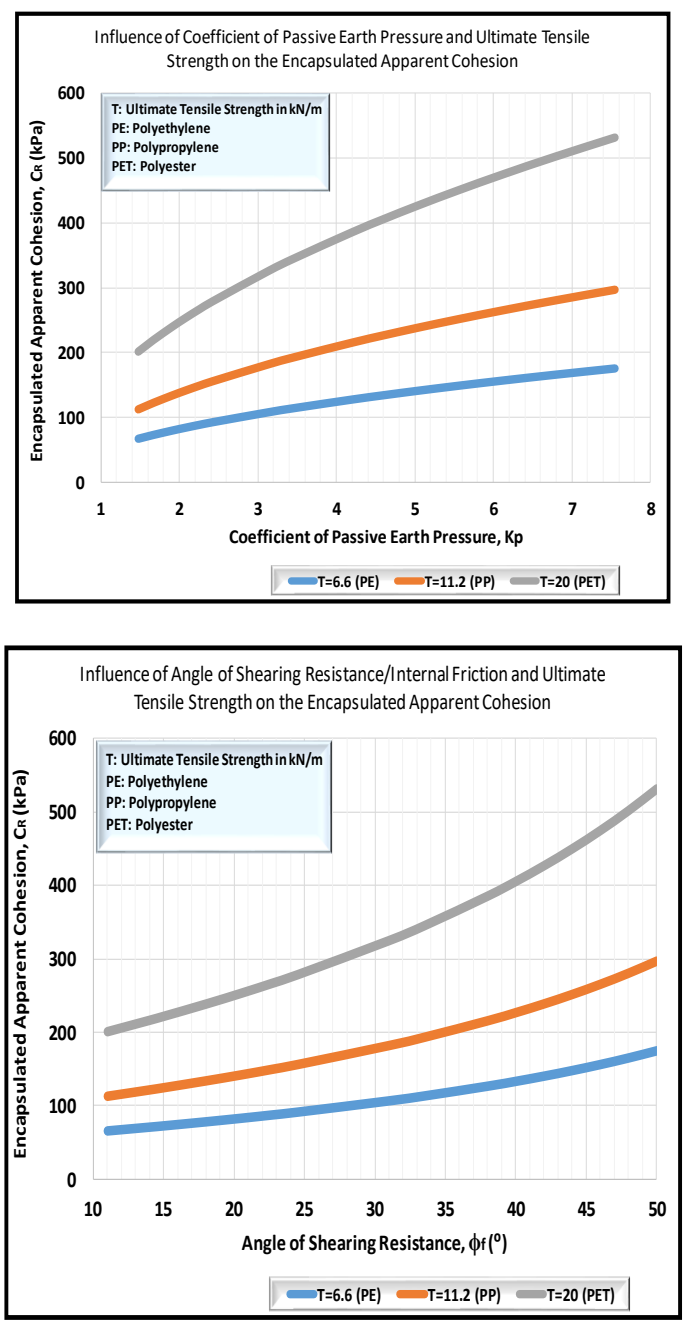

Fig. 13. Effects of ultimate tensile strength of soilbag fabric on encapsulated apparent cohesion with varying: a) coefficient of passive earth pressure; and, b) angle of shearing resistance.
On the other hand, the apparent intrinsic cohesion, $c_{R}$ is derived on the basis of Equations (4), (22) and (29) taking the effect of the apparent confining stress, $\Delta \sigma_{3 R}^{\prime}$ into account. Rearranging the terms in Equation (4) as an expression defining $c_{R}$, yields:

$$
c_{R}=\frac{\left(\sigma_{1 f}^{\prime}+\Delta \sigma_{3 R}^{\prime} K_{p}\right)}{2 \sqrt{K_{p}}}
$$

Substituting for $\sigma_{1 f}^{\prime}$ and $\Delta \sigma_{3 R}^{\prime}$ from Equations (22) and (29) the following expression is obtained.

$$
c_{R}=\frac{T\left(4 K_{p}-1\right)}{4 H \sqrt{K_{p}}(H-\delta)}\left[1-\frac{\delta}{H}\right]
$$

Consequently, the apparent intrinsic cohesion, $c_{R}$ can be quantitatively evaluated from Equation (32).

$$
c_{R}=\frac{T\left(4 K_{p}-1\right)}{4 H \sqrt{K_{p}}}
$$

Note that Equations (19) Equation (32) can further be simplified by considering the specified height/thickness as a constant value, $H=0.1 \mathrm{~m}$.

\section{3) Model and full-scale testing}

In order to advance the understanding and capacity to elucidate the mechanisms of fully encapsulated confinement systems and establish standard methods of strength, stiffness and performance evaluation, it is imperative that innovative modelling and full-scale testing is undertaken rigorously. Guidelines on the appropriate and innovative methods of testing are provided in [8].

\section{4) Field (in-situ) investigations}

The most pragmatic method of evaluating the strength, bearing capacity, stiffness and degree of performance enhancement is to perform field investigations and in-situ testing. The methods of in-situ testing that have been performed to evaluate the bearing capacity of do-nou improved road sections include the DCP (dynamic cone penetrometer) for determining the CBR (California Bearing Ratio) and the $\mathrm{PB} / \mathrm{LT}$ (plate bearing/loading tests).

Figure 14 depicts the recommended mode of determining stiffness (surface modulus) from PB/LT (plate bearing/loading) measurements.

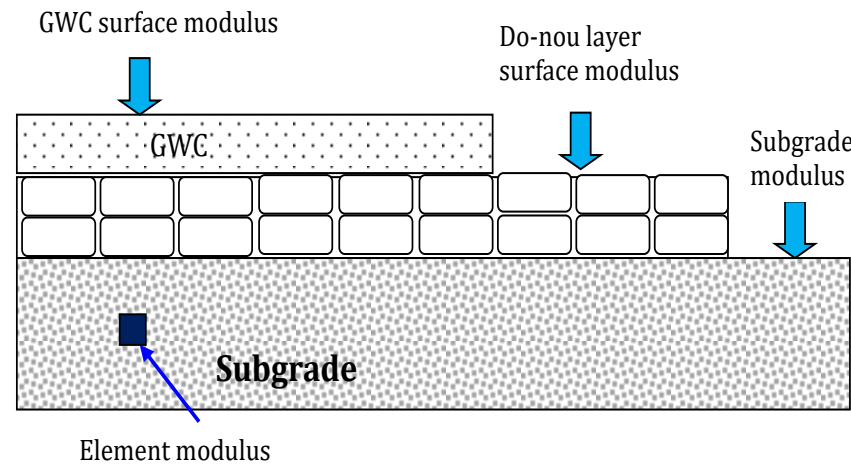

Fig. 14. Mode of determining stiffness (elastic modulus) from PB/LT (plate bearing/loading) measurements (MTRD Evaluation Report No. 1314 of April, 2018).

\section{Anaysis of size and shape effects}

As can be unequivocally inferred from practically all the foregoing Equations $1 \sim 32$, the size and shape of the WECS soilbags has significant influence on the mobilization of tensile 
stresses hence the development of the strength and stiffness of the fill material. It is therefore imperative that the dimensions specified at the outset are strictly adhered to.

\section{E. Influence of number of layers}

It is imperative to determine the appropriate number of layers required. The number of do-nou layers required is, understandably, dependent on the tensile strength of the WECS bag, bearing strength/capacity/stiffness of the subgrade and the delineating geotechnical/environmental conditions.

The influence of the number of do-nou stacked layers is to be quantified and incorporated in the design for cases whereby multiple layers are necessary as depicted in Figures 15 and 16.
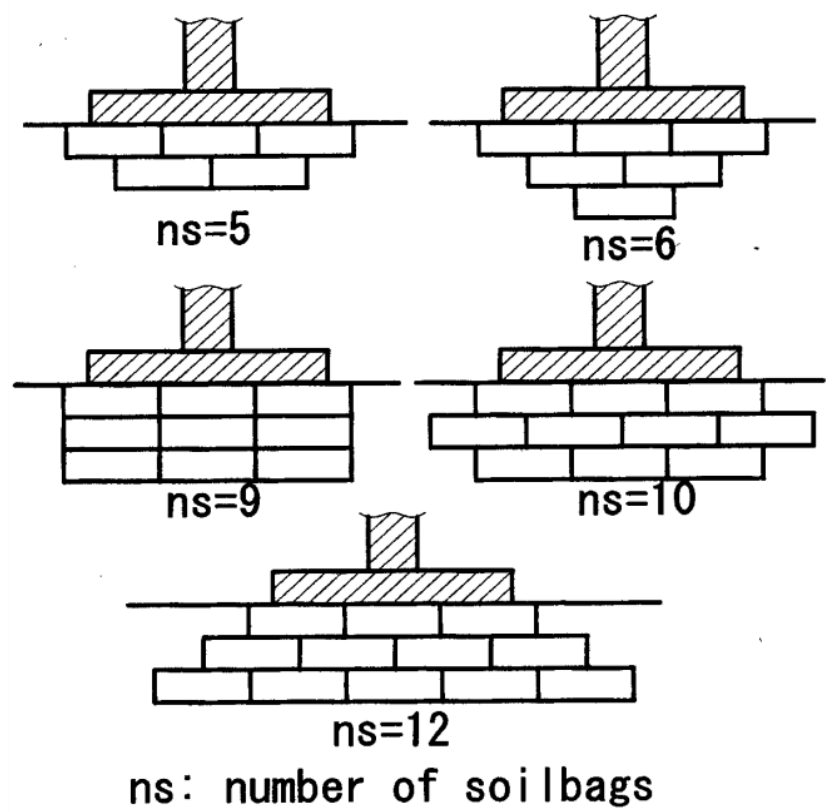

Fig. 15. Various WECS do-nou cross-sectional layout configuration (Matsuoka and Liu, 2003).

The appropriate number of soilbag (do-nou) layers required, $N_{D L}^{r e q .}$ can be computed from the model defined in Equation (33), which takes into account the deformation resistance of the natural subgrade.

$N_{D L}^{r e q .}=\left(-6 \times 10^{-5} M_{R, S G}^{2}+0.078 M_{R S G}\right)^{-1} \times F_{S}$

where, $M_{R S G}$ is the resilient modulus of the natural (existing) subgrade prior to improvement and $F_{S}$ is the factor of safety to cater for site conditions, installation/construction deficiencies and ramification. It is recommended that the factor of safety is limited within the range: $1.5 \leq F_{S} \leq 2$. Equation (33) is adopted in generating Table $\mathrm{V}$, which is to be employed in design.
TABLE V. APPROPRIATE NUMBER OF WECS (SOILBAG) LAYERS REQUIRED BASED ON SUBGRADE STIFFNESS.

\begin{tabular}{|r|r|c|c|c||}
\hline \multicolumn{2}{||r|}{ Site Conditions } & Normal & Critical & $\begin{array}{c}\text { Highly } \\
\text { Critical }\end{array}$ \\
\hline $\begin{array}{r}\text { Factor of } \\
\text { Safety, Fs }\end{array}$ & 1.5 & 1.75 & \multicolumn{1}{c|}{} \\
\hline Priority & & 1 & 2 & 3 \\
\hline $\begin{array}{r}\text { Subgrade } \\
\text { Resilient } \\
\text { Modulus, } \\
\text { MR (Mpa }\end{array}$ & $\begin{array}{c}\text { Equivalent } \\
\text { CBR (\%) }\end{array}$ & \multicolumn{4}{|c|}{ Number of Do-nou Layers Required, } \\
\hline 6 & 1 & \multicolumn{3}{|c|}{ NDL (No.) } \\
\hline 12 & 2 & 1.6 & 1.8 & 2.1 \\
\hline 18 & 3 & 1.1 & 1.3 & 1.4 \\
\hline 24 & 4 & 0.8 & 1.0 & 1.1 \\
\hline 29 & 5 & 0.7 & 0.8 & 0.9 \\
\hline 34 & 6 & 0.6 & 0.7 & 0.8 \\
\hline 39 & 7 & 0.5 & 0.6 & 0.7 \\
\hline 44 & 8 & N/A & 0.5 & 0.6 \\
\hline 49 & 9 & N/A & 0.5 & 0.5 \\
\hline 54 & 10 & N/A & N/A & 0.5 \\
\hline \hline
\end{tabular}

Notes: $N_{D L}^{\text {req. }}=0.5$ to be rounded to: $N_{D L}^{\text {req. }} \geq 1$ depending on the site conditions@Engineers judgement: N/A - Not Applicable

F. Quantitative evaluation of influence of number of vertically stacked layers

Results from model experimental testing conducted on WECS indicate that the bearing capacity of do-nou basically increases by the square exponent of the ratio of the increased to the original area: $\left(A^{\prime} / A_{\text {orig. }}\right)^{2}$, which applies both in plane and cross-sectional perspectives [2]. Based on this concept and taking the soilbag edge reduction and the effects of installation/construction deficiencies and ramification, the model defined in Equation (34) should be applied in the evaluation of the influence of stacked layers.

$$
\sigma_{1 f}^{\prime}=\left(\frac{T}{2(H-\delta)}\right)\left[4 K_{p}-1\right] \times\left\{\frac{(B H)_{N_{L}>1}\left[1-0.1\left(N_{L}-1\right)\right] \times N_{L}}{(B H)_{N_{L}}=1}\right\}^{2 f_{R}}
$$

where, $N_{L}=$ number of stacked layers and $f_{R}=$ partial factor to account for installation/construction deficiencies, $f_{c d}$ and ramification, $f_{n}$ whereby $f_{R}=f_{c d} \times f_{n}=0.8 \times 0.91=$ 0.727. This implies the square exponent reduces to 1.455 .

Employing the ratio conversion concept, Equation (34) is simplified to:

$$
\sigma_{1 f}^{\prime}=\left(\frac{T}{2(H-\delta)}\right)\left[4 K_{p}-1\right] \times\left\{\frac{\left[(H)_{N_{L}>1}\right]^{2}\left[1-0.1\left(N_{L}-1\right) \times N_{L}\right]}{\left[(H)_{N_{L}=1}\right]^{2}}\right\}^{1.455}
$$

A similar principle is used in developing Equation (36), which mathematically defines the resulting loads at failure.

$$
\begin{gathered}
P_{L}=\left(\frac{T}{2(H-\delta)}\right)\left[4 K_{p}-1\right] \times 16(H+\delta)^{2} \times \\
\left\{\frac{\left[(H)_{N_{L}>1}\right]^{2}\left[1-0.1\left(N_{L}-1\right) \times N_{L}\right]}{\left[(H)_{N_{L}=1}\right]^{2}}\right\}
\end{gathered}
$$

Equations (35) and (36) are employed in generating Table VI, which summarize bearing capacity and load values, that areto be adopted in design of WECS do-nou foundations to a level of up to 3 (three) vertically stacked soilbag layers. 
Note that the ultimate tensile strength of the Kenyan manufactured polypropylene soilbag fabric $\left(T_{\text {ult. }}=11.2 \mathrm{kN} /\right.$ $m$ ) is adopted in these computations.

The apparent increase in intrinsic confining stress and intrinsic cohesion can be evaluated from Equations (37) and (38).

$$
\begin{gathered}
\Delta \sigma_{3 R}^{\prime}=\frac{T\left(4 K_{p}-1\right) \delta}{2 H(H-\delta) K_{p}} \times\left\{\frac{\left[(H)_{N_{L}>1}\right]^{2}\left[1-0.1\left(N_{L}-1\right) \times N_{L}\right]}{\left[(H)_{N_{L}=1}\right]^{2}}\right\}^{1.455} \\
c_{R}=\frac{T\left(4 K_{p}-1\right)}{4 H \sqrt{K_{p}}} \times\left\{\frac{\left[(H)_{N_{L}>1}\right]^{2}\left[1-0.1\left(N_{L}-1\right) \times N_{L}\right]}{\left[(H)_{N_{L}=1}\right]^{2}}\right\}^{1.455}
\end{gathered}
$$

where, $L=$ length of the WECS do-nou (soilbag). Note that these models are simplified based on the fact that the standard specifications stipulated are: $L=B=0.4 \mathrm{~m}$ and $H=0.1 \mathrm{~m}$.

\begin{tabular}{|c|c|c|c|c|c|c|c|c|c|c|c|c|}
\hline \multirow{4}{*}{\begin{tabular}{|c|}
$\begin{array}{c}\text { Ref. } \\
\text { Bearing } \\
\text { Capacity }\end{array}$ \\
\end{tabular}} & \multicolumn{12}{|c|}{ VERTICALLY STACKED WECS LAYERS. } \\
\hline & \multicolumn{3}{|c|}{\begin{tabular}{l|l} 
Tutt. $(\mathrm{kN} / \mathrm{m})$ & 11. \\
\end{tabular}} & & & & & & & & & \\
\hline & \multicolumn{12}{|c|}{ Bearing Capactities for Vanying Vertically Stacked Do-nou Layers } \\
\hline & \multicolumn{2}{|c|}{ No. of Stacked layers } & & 2 & & 4 & 5 & 6 & 7 & 8 & 9 & 10 \\
\hline $\begin{array}{c}\text { Equiv. CBR } \\
(\%)\end{array}$ & $\begin{array}{c}\text { AF/ASR, } \\
\phi t x\end{array}$ & $\begin{array}{l}\text { Coefficient of } \\
\text { Passive Earth } \\
\text { Pressure, } \mathrm{K}_{\mathrm{p}}\end{array}$ & \multicolumn{10}{|c|}{ Bearing Capacty, Oit (KPa) } \\
\hline 10 & 15 & 1.698 & 351 & 927] & 1610 & 2354 & 3129 & 3916 & 4698 & 5463 & 6200 & 6011 \\
\hline 19 & 20 & 2.040 & 433 & 1145 & 1989 & 2008 & 3866 & 4838 & 5805 & 6750 & 7661 & 852 \\
\hline 31[ & 25 & 2.464 & 536 & 1447 & 2461 & 3597 & 4783 & 5985 & 7181 & 8350 & 9477 & 10549 \\
\hline 40] & 28 & 2.770 & 610 & 1612 & 2801 & 4095 & 5444 & 6813 & 8173 & 9504 & 10787 & 1200 \\
\hline 47] & 30 & 3.000 & 666 & 1760 & 3057 & 4669 & 5941 & 7435 & 8920 & 10372 & 11772 & 1310 \\
\hline 54 & 32. & 3.255 & 728 & 1923 & 3340 & 4882 & 6491 & 8123 & 9746 & 111333 & 12862 & 143 \\
\hline 62 & 34 & 3.537 & 796 & 2103 & 3654 & 5341 & 7101 & 8887 & 10662 & 123988 & 14072 & 1566 \\
\hline 71 . & 36 & 3.852 & 872 & 2305 & 4003 & 5853 & 7781 | & 9738 & 11683 & 13585 & 15419 & 1716 \\
\hline 80 & 38 & 4.204 & 957 & 2530 & 43355 & 6425 & 8542 & 10689 & 12824 & 149913 & 16925 & 1883 \\
\hline 90 & 40 & 4.599 & 1053 & 2783 & 4834 & 7067 & 9395 & 11758 & 14106 & 16403 & 18617 & 2072 \\
\hline 100 & 42 & 5.045 & 1161 & 3068 & 5329 & 7791 & 10358 & 12963 & 15552 & $18084 \mid$ & 20525 & 2284 \\
\hline 1111 & 44 & 5.550 & 1283 & 3391 & 58891 & 8612 & 11450 & 14329 & 17191 & 19990 & 22688 & 25253 \\
\hline 123. & 46 & 6.126 & 1423 & 3760 & 6531 & 9548 & 12695 & 15886 & 19060 & 22163 & 25154 & 27998 \\
\hline 135 & 48 & 6.786 & 1583 & 4183 & 7265 & 10621 & 14121 & 17672 & 21202 & 24654 & 27981 & 31145 \\
\hline 148 & 50 & 7.549 & 1767 & 4670 & 8112 & 11860 & 15768 & 19732 & 23674 & 27529 & 31244 & 34776 \\
\hline
\end{tabular}

TABLE VI. BEARING CAPACITIES FOR VARYING NUMBER OF

\section{G. Effects of lamination in multi-layered WECS}

In most cases, for soft ground reinforcement/improvement, the WECS do-nou technology requires multi-layer piling as shown in Figure 16.

Model and full-scale experimental testing results indicate that the effect of lamination is to increase the ultimate tensile strength, $T_{\text {ult }}$. by approximately the number of laminates depending on the axial strain at which the $T_{\text {ult }}$ is determined. Unless otherwise intentional modified, WECS do-nou laminates would usually be two faces notwithstanding the number of piled layers as can be derived from Figure 16. In this case it can be seen that the middle portion of the three layer pile on the RHS is laminated on both the top and bottom faces (two face lamination). This effect has yet to be investigated. This notwithstanding, the overlaying and under-laying layers are each single face laminated.

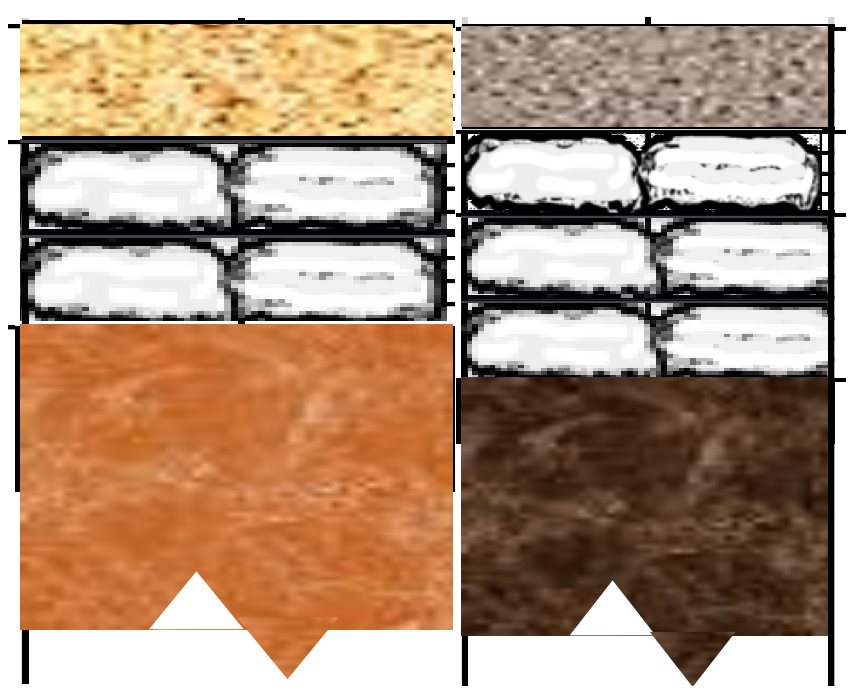

Fig. 16. Example of laminated soilbags: Effect of lamination depending on number of WECS do-nou layers.

The model defined in Equation (39), which is used in computing the values summarized in Table VII for two laminates $\left(N_{\text {lam. }}=2\right)$ enable the accounting for the influence of lamination in design.

$$
T_{\text {ult.lam. }}=\left(-0.3595 N_{\text {lam. }}^{0.9737} \varepsilon_{a}^{2}+10.45 N_{\text {lam. }}^{0.9916} \varepsilon_{a}\right) \times \frac{T_{u l t .}}{T_{\text {ult. }}^{\text {ref. }}}
$$

where $T_{\text {ult.lam. }}$ and $T_{\text {ult. }}^{\text {ref. }}=70 \mathrm{kN} / \mathrm{m}$ are the resulting laminated and the reference ultimate tensile strengths, respectively.

\section{TABLE VII. SUMMARY OF RESULTING ULTIMATE TENSILE STRENGTH DUE TO SINGLE FACE LAMINATION $\left(N_{\text {lam. }}=2\right)$}

\begin{tabular}{|r|r|r|r|}
\hline $\begin{array}{r}\text { Material } \\
\text { (kN/m) }\end{array}$ & PE & PP & PET \\
\hline Origin & China & Kenya & Japan \\
\hline $\begin{array}{c}\text { Axial } \\
\text { Strain, } \\
\text { (\%) }\end{array}$ & \multicolumn{4}{|c|}{$\begin{array}{l}\text { Resulting Ultimate Tensile Strength } \\
\text { Due to Single Face Lamination Effect, } \\
\text { Tult.lam. (kN/m) }\end{array}$} \\
\hline 3 & 5.3 & \multicolumn{3}{|c|}{9.0} & 16.0 \\
\hline 4 & 6.8 & 11.5 & 20.5 \\
\hline 6 & 9.4 & 15.9 & 28.4 \\
\hline 8 & 11.4 & 19.4 & 34.6 \\
\hline 10 & 12.9 & 21.9 & 39.2 \\
\hline 11 & 13.5 & 22.9 & 40.9 \\
\hline 12 & 13.9 & 23.6 & 42.2 \\
\hline 13 & 14.2 & 24.1 & 43.1 \\
\hline 14 & 14.4 & 24.4 & 43.6 \\
\hline 15 & 14.4 & 24.5 & 43.7 \\
\hline 16 & 14.3 & 24.3 & 43.3 \\
\hline 17 & 14.1 & 23.9 & 42.6 \\
\hline 18 & 13.7 & 23.2 & 41.5 \\
\hline 19 & 13.2 & 22.4 & 40.0 \\
\hline 20 & 12.6 & 21.3 & 38.0 \\
\hline
\end{tabular}

Notes: PE-Polyethylene; PP-Polypropylene; Polyester

It is recommended that the values $T_{\text {ult.,lam. }}$ highlighted in grey be adopted since they are the maximum values determined @ $\varepsilon_{a}=15 \%$, which is almost a standard value for determining the ultimate tensile strengths for woven geotextiles.

\section{BASIC DESIGN CRITERIA}

\section{A. Structural design criteria}

The conceptual basis of the structural design criteria developed is focused on the effective characterization of the WECS do-nou (soilbag) encapsulation characteristics based on 
the soil mechanics theories and geotechnical engineering concepts introduced in the preceding Section II. In particular, the following considerations and attributes constitute the structural design criteria: i) under dynamic loading, the wheel loading applied to a soilbag reinforced layer will usually be multi-directional; ii) a wheel passage over a single soilbag impacts force vectors through the Mechanically Stabilized Layer (MSL) which vary in time, direction and magnitude; iii) vertical stresses impacted predominantly by live load surcharges from traffic dynamic loading are dispersed in the mode and pattern portrayed in a Westergaard model; iv) stress $\sim$ strain distribution primarily depends on the index characteristics of soilbag product, the intrinsic mechanical; strength and stiffness (elastic modulus) properties of the fill geomaterials and the degree/extent of the encapsulation confinement effect; v) lateral restraint/confinement of the base and subgrade is achieved through friction and bonding of the layer geomaterials and the WECS; vi) increase in the system bearing capacity is gained by diverting the potential bearing capacity failure surface to develop along alternate, higher shear strength surfaces both for the soilbag fill $g$ and the pavement and subgrade layer geomaterials; and vii) membrane support of the wheel loads is only achievable under considerably high strain conditions within the soilbag hence its application should be limited to temporary road pavements.

\section{B. Failure criteria}

The The failure criterion of the composite do-nou consisting of the soil and the bag is based on the Limit State philosophy entailing ultimate and serviceability states.

1) Failure criterion based on shear strength

It has been explicitly demonstrated in the preceding Section II that WECS soilbags exhibit both compressive and tensile characteristics. It was also shown that the compressive strength decreases with a corresponding decrease in the apparent cohesion, $c(\delta)$ when subjected to inclined external loading $(\delta>0)$ [Equation (11)]

As shown in Figure 17, the failure criterion of the composite soilbags is based on Mohr's stress diagram [2]. As can be inferred from this schematic representation, failure assumes two major conditions including: i) the confining stress is non-prevalent $\left(\sigma_{3}=0\right)$; and ii) both the soilbag fabric and fill geomaterial fail simultaneously. In this case, the soilbags will exhibit tensile strength when connected (refer to subSection D). The integral parameters that delineate the failure criterion are the vertical stress, angle of shearing resistance and the apparent cohesion.

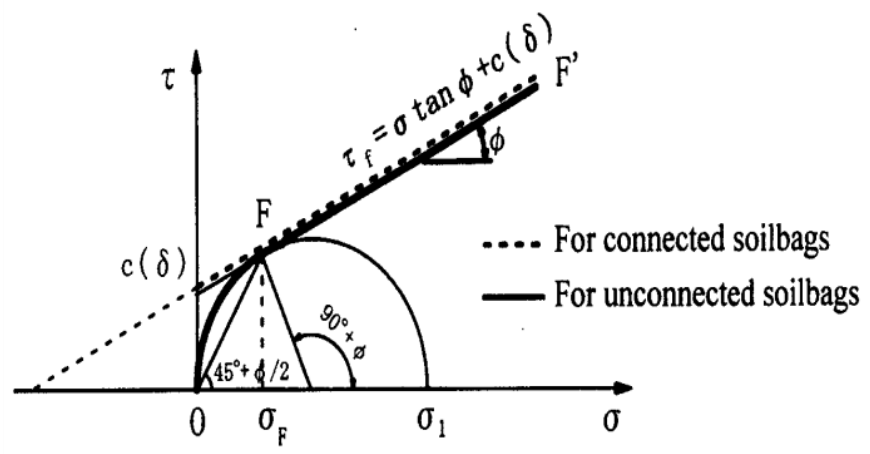

Fig. 17. Failure criterion of composite WECS soilbags (Matsuoka and Liu, 2003).

\section{2) Serviceability criterion based on rut depth}

The serviceability criterion deemed to be the maximum rut depth. In this case, a maximum rut depth of $15 \mathrm{~mm}$ is considered the allowable value hence non-serviceability compliance is designated when $R_{d, \max } \geq 15 \mathrm{~mm}$.

\section{Area coverage ratio}

As can be observed from Figures 18 and 19, soilbags are installed as discrete reinforcing elements in this case. It has been evident from various trials and road sections improved using the Do-nou technology that the $5 \mathrm{~cm}$ spacing provided as a tolerance or compaction is never closed perfectly.

\section{Edge Effects}

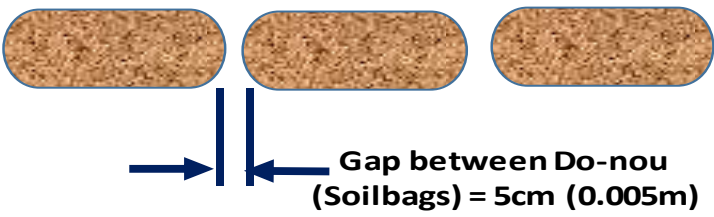

Fig. 18. Gap provision for compaction tolerance of WECS soilbags.

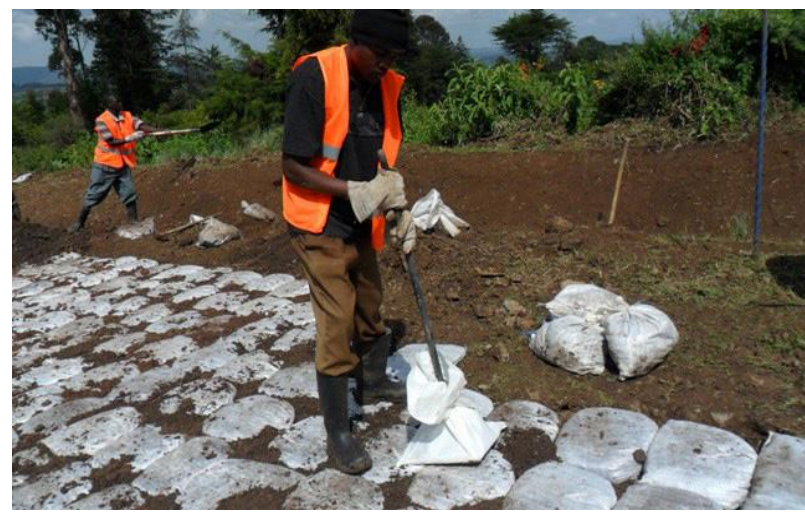

Fig. 19. Installation, compaction and filling of gaps between WECS soilbags

In order to account for these gaps, the area coverage ratio is introduced as a reduction factor to be applied to the effective bearing strength/capacity and strength parameters, which are highly dependent on the area coverage of the soilbags. In consideration of the gaps and edge effects, the area coverage ratio shall be computed on the basis of Equation (40).

$$
R_{C}=\frac{\left(B-\Delta_{B}\right) \times\left(L-\Delta_{L}\right)}{B_{\text {orig. }} \times L_{\text {orig. }}}
$$

Based on the WECS soilbag dimensional specifications provided in this paper, which are standard and remain constant, the area coverage ratio is designated at $R_{C}=0.81$.

\section{Connectivity of WECS bags}

The effects of connection on tensile strength and their contribution to yield strength and the failure criterion can be derived from Figure 17. It has also been derived from the analysis and structural performance evaluation of the trial and road sections improved using the Do-nou technology in Kenya that these gaps culminate in drifting of the soilbags particularly in areas predominated with problematic soils.

On the other hand, it can be derived from Figure 24 that for permanent structures constructed in Japan using the Do-nou technology, the soilbags are connected. Although further investigations are necessary in order to develop appropriate 
guidelines regarding this aspect, it is advisable that the soilbags are connected through seaming in the field.

\section{E. Applicable partial factors}

In designing geo-structures with do-nou application, reduction factors have to be employed to mainly account for durability, installation damage/construction deficiencies, creep reduction and uncertainties in consideration of the donou material properties and soil interaction characteristics [7]. The partial (reduction) factors to be employed for the LongTerm Design Strength (LTDS) of soilbags reinforced/improved embankments and pavements are presented in Table VIII.

The data in Table VIII is then used to determine the allowable working stress of the soilbag reinforcement from the expression in the following Equation 41. The values in brackets are the equivalent partial factors.

$$
T_{a}=\frac{T_{u l t}}{\left(R F_{D} \times R F_{I D} \times R F_{C R}\right)}(k N / m)
$$

TABLE VIII. PROPOSED PARTIAL (REDUCTION) FACTORS

\begin{tabular}{|c|c|c|c|}
\hline 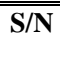 & Particulars & $\begin{array}{l}\text { Typical } \\
\text { Values }\end{array}$ & $\begin{array}{c}\text { Proposed } \\
\text { Values }\end{array}$ \\
\hline 1. & Durability Reduction Factor, $R F_{D}$ & $1.2(0.833)$ & $1.2(0.833)$ \\
\hline 2. & $\begin{array}{l}\text { Installation Damage Reduction Factor, } \\
R F_{I D}\end{array}$ & $1.25(0.8)$ & $1.25(0.8)$ \\
\hline 3. & Creep Reduction Factor, $R F_{C R}$ & $1.66(0.6)$ & $1.5(0.667)$ \\
\hline 4. & $\begin{array}{l}\text { Factor of Safety against Uncertainties, } \\
F S_{\text {unc }}\end{array}$ & $1.5(0.667)$ & $1.1(0.909)$ \\
\hline
\end{tabular}

\section{F. Design life}

The design life shall be equivalent to the in-service life and shall be designated at a period that is compatible to the LTDS (long-term design strength).

\section{DEVELOPMENT OF DESIGN CATALOGUES}

\section{A. Foundation structural configuration}

The WECS do-nou foundation, as per the definition of this paper, consists of the structural subgrade thickness and the soilbag layer(s) as depicted in Figure 20.

The integral criteria of adopting the WECS Do-nou technology is to ensure the achievement of a sound foundation that will effectively support the pavement structure over an extended period comprising of the design life and rehabilitation extension. It is therefore imperative to determine the appropriate number of do-nou layers required. As demonstrated in the preceding sections, the number of do-nou layers required is, understandably, dependent on the bearing strength/capacity/stiffness of the subgrade and the delineating geotechnical/environmental conditions.

The influence of the number of vertically stacked do-nou layers is to be quantified and incorporated in the design for cases whereby multiple layers are necessary.

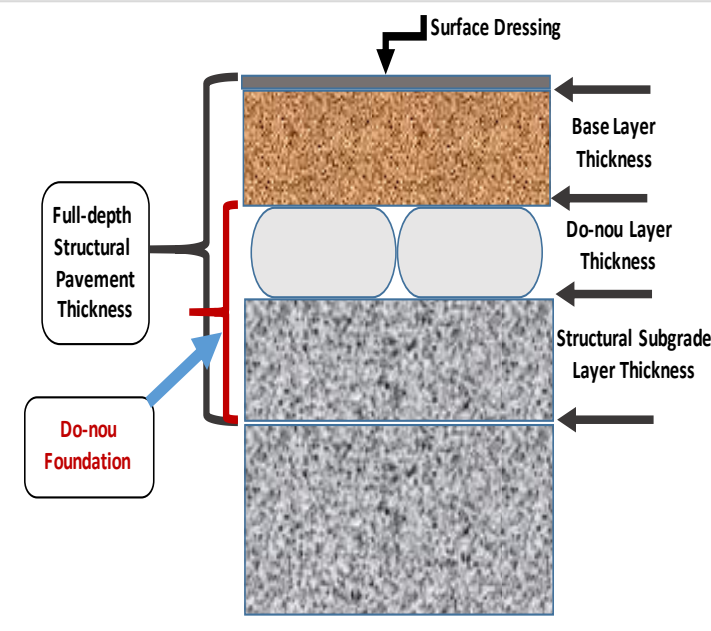

Fig. 20. Depiction of various layer types and definition of WECS (Do-nou) foundation and subgrade structural thickness.

The appropriate number of do-nou layers required, $N_{D L}^{r e q .}$ as computed from the model defined in Equations (33) and (42), which take into account the deformation resistance of the natural subgrade, are summarized in Table V.

In cases whereby it is deemed by the Engineer that the site conditions are critically problematic, additional do-nou layers based on a design review may be incorporated upon review and approval by the Chief Engineer.

Note that Table $\mathrm{V}$ is generated based on the specifications stipulated in [6] considering Class G8 natural material with an initial target improvement to Foundation Class F3 (Equivalent Subgrade Class S5) whereby the fill geomaterial is reinforced to Class G22, at a relative compaction of 95\%MDD using a soilbag fabric with an ultimate tensile strength of $11.2 \mathrm{kN} / \mathrm{m}$ $\left(T_{\text {ult. }}=T=11.2 \mathrm{kN} / \mathrm{m}\right)$. In this case, the initial target surface (composite) modulus is $125 \mathrm{MPa}$. Table IX provides computational details. Note that further improvement/reinforcement is anticipated with progressive consolidation in the initial stages of traffic loading.

TABLE IX. ELASTIC MODULUS (STIFFNESS) VALUES FOR THE WECS COMPOSITE STRUCTURAL LAYERS.

\begin{tabular}{|c|c|c|c|c|c|c|c|c|c|c|c|c|c|}
\hline \multirow{4}{*}{\multicolumn{2}{|c|}{\begin{tabular}{|l} 
Do-nou Natural Fill \\
Material Calssification \\
and Reference Bearing \\
Capacity
\end{tabular}}} & \multirow{2}{*}{\multicolumn{2}{|c|}{$\begin{array}{l}\text { Tult. }(\mathrm{kN} / \mathrm{m}) \\
\text { Tall. }(\mathrm{kN} / \mathrm{m})\end{array}$}} & \multicolumn{3}{|c|}{6.60} & \multicolumn{3}{|c|}{11.20} & \multicolumn{3}{|c|}{20.00} & \\
\hline & & & & \multicolumn{3}{|c|}{2.67} & \multicolumn{3}{|c|}{4.53} & \multicolumn{3}{|c|}{8.08} & \\
\hline & & \multicolumn{12}{|c|}{ Elastic Modulus (Stifffess) for Varving Vertically Stacked Do-nou Compositestructural Layers } \\
\hline & & \multicolumn{2}{|c|}{ No. of Stacked Layers } & & & & & & & & & & \\
\hline $\begin{array}{c}\text { PDG } 1 \\
\text { Designation }\end{array}$ & $\begin{array}{c}\text { Equiv. CBR } \\
(\%)\end{array}$ & $\begin{array}{c}\text { AfF/ASR, } \\
\phi_{t x}\end{array}$ & $\begin{array}{l}\text { Coefficient of } \\
\text { Passive Earth } \\
\text { Pressure, } K_{p}\end{array}$ & \multicolumn{10}{|c|}{ Elastic Modulus (Stiffness) Values for Donou Composite Structural Layers, E0 (MPa) } \\
\hline 65 & & 11 & 1.472 & 18 & 43 & 68 & 29 & 67 & 106 & 48 & 108 & 196 & 387 \\
\hline 68 & & 14 & 1.638 & 20 & 48 & 76 & 32 & 74 & 118 & 54 & 121 & 239 & 521 \\
\hline 610 & 1 & 15 & 1.698 & 21 & 50 & 79 & 34 & 77 & 123 & 56 & 126 & 257 & 579 \\
\hline 615 & 1 & 18 & 1.894 & 23 & 55 & 87 & 38 & 85 & 140 & 62 & 144 & 326 & 809 \\
\hline 620 & 2 & 21 & 2.078 & 26 & 60 & 95 & 41 & \begin{tabular}{|l|}
93 \\
\end{tabular} & \begin{tabular}{|l|l|}
157 \\
\end{tabular} & 68 & \begin{tabular}{|l|l|}
162 \\
\end{tabular} & 408 & 1088 \\
\hline 625 & 2 & 23 & 2.257 & 28 & 65 & 103 & \begin{tabular}{|l|}
45 \\
\end{tabular} & 101 & \begin{tabular}{|l|l|}
176 \\
\end{tabular} & 73 & 182 & 507 & 1430 \\
\hline 630 & 3 & 25 & 2.417 & 30 & 70 & 110 & 48 & 108 & 195 & 78 & 202 & 614 & 1800 \\
\hline 650 & 5 & 31 & $\begin{array}{l}3.124 \\
\end{array}$ & 39 & 88 & 144 & 61 & 141 & 312 & 98 & 330 & 1345 & $\begin{array}{l}43255 \\
\end{array}$ \\
\hline 660 & 6 & 34 & 3.464 & 43 & 96 & 163 & 67 & 159 & 394 & 108 & 419 & 1880 & 6161 \\
\hline \multirow[t]{7}{*}{680} & 8 & 38 & 4.204 & 51 & 115 & 216 & 79 & 209 & 649 & 131 & 698 & 3571 & 7980 \\
\hline & 9 & 40 & 4.599 & 55 & 125 & 253 & 86 & 243 & 838 & 144 & 905 & 48233 & 84855 \\
\hline & 10 & 42 & 5.045 & 60 & 138 & 302 & 93 & 289 & 1103 & 161 & 1195 & 6572 & 9035 \\
\hline & 11 & 44 & 5.550 & 65 & 154 & 370 & 101 & 352 & 1480 & 182 & 1607 & 7546 & 9638 \\
\hline & 12 & 46 & 6.126 & 71 & 174 & 467 & 110 & 442 & 2020 & 210 & 2199 & 8065 & 10301 \\
\hline & 13 & 48 & 6.786 & 77 & 201 & 607 & 121 & 572 & 2806 & 249 & 3059 & 8638 & 11033 \\
\hline & 14 & 50 & 7.549 & 85 & 238 & 813 & 135 & \begin{tabular}{|l|}
763 \\
\end{tabular} & 3965 & 305 & 4326 & 9274 & 11845 \\
\hline
\end{tabular}




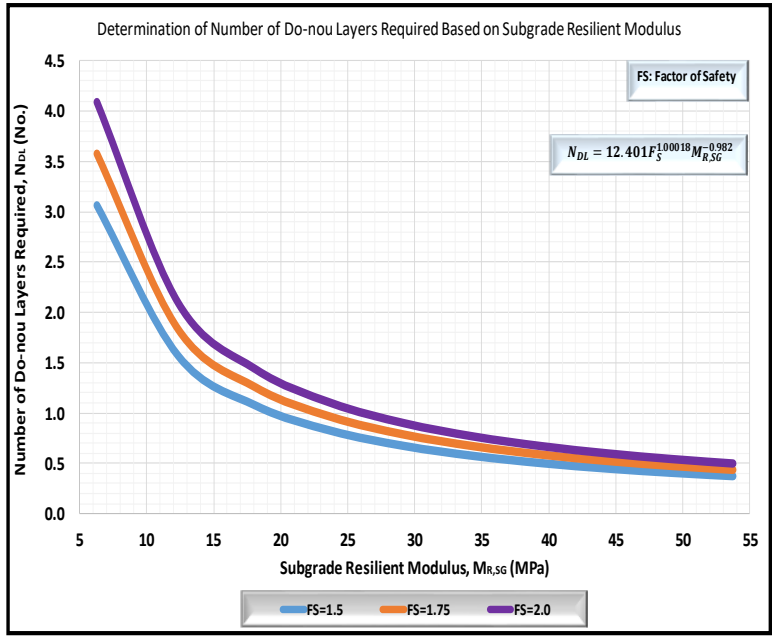

Fig. 21. Graphical method of determining number of WECS soilbag (do-nou) layers required based on subgrade stiffness.

On the other hand, Figure 21. depicts the graphical method of determining the number of do-nou layers required based on subgrade stiffness, which is defined in terms of the resilient modulus. The main model is defined in Equation (33). An alternative counter-check model is expressed in Equation (42).

$$
N_{D L}=12.401 F_{S}^{1.00018} M_{R, S G}^{-0.982} \times f_{\text {str }, D L}
$$

\section{B. Full-depth structural configuration}

As outlined under Section II of this paper and [6], the pavement structural configurations selected and provided within the Standard Pavement Structure Type, which define the Design Catalogues, are developed on the basis of the thickness-modulus ratio concepts that ensure the achievement of a balanced pavement structure. In so doing, due consideration has been made to the following: i) a structurally balanced pavement is realized; ii) achievement of enhanced strength, stiffness and deformation resistance as a result of increasing the vertically stacked WECS soilbags (do-nou) layers; iii) influence of cross-sectional layout configuration as shown in Figure 15, is taken into account; and iv) the subbase layer is wholly expunged from the pavement structural configuration as part of the VE (value engineering benefit.

\section{Application of the thickness-modulus ratio concept}

When a pavement structure undergoes vibrational dynamic loading under heavy and/or progressively continuous traffic, it experiences prolonged residual vibrations. The intensity of such residual vibrations highly depends on the absorbent capacity of the flexible pavement, which is defined by the reciprocal balance between the stiffness (elastic modulus) of the neighbouring layers. Prolonged reverberation of such stress can have detrimental effects on the structural soundness of the pavement. The thickness-modulus ratio concepts are employed as a geotechnical engineering means of mitigating this problem by ensuring reciprocal compensation between the thickness and the elastic modulus (stiffness) of the neighbouring layers as can be derived from the model defined in Equation (43).

$$
\frac{t_{D F}}{t_{B C}}=\sqrt[3]{\left\{\left[\frac{E_{B C}}{E_{D F}}\right] \times\left[\frac{\left(1-v_{D F}^{2}\right)}{\left(1-v_{B C}^{2}\right)}\right]\right\}}=\left\{\left[\frac{E_{B C}}{E_{D F}}\right] \times\left[\frac{\left(1-v_{D F}^{2}\right)}{\left(1-v_{B C}^{2}\right)}\right]\right\}^{1 / 3}
$$

On the other hand, the layer Poisson's ratios, $v_{P L}$ can be computed from the respective pavement layer stiffness based on the model defined in Equation (44).

$$
v_{P L}=-0.063 \ln \left(E_{0, P L}\right)+0.864
$$

where; $t_{D F} ; E_{D F} ; v_{D F}=$ WECS Do-nou Foundation layer thickness/elastic modulus/Poisson's ratio, $t_{B C} ; E_{B C} ; v_{B C}=$ Base Course layer thickness/elastic modulus/Poisson's ratio, and $M_{R, S G}=$ subgrade resilient modulus, whilst $P L$ denotes pavement layer.

To determine the appropriate or required base course thickness, Equation (45) can be rewritten as:

$$
t_{B C}=t_{D F} \times\left\{\left[\frac{E_{B C}}{E_{D F}}\right] \times\left[\frac{\left(1-v_{D F}^{2}\right)}{\left(1-v_{B C}^{2}\right)}\right]\right\}^{-1 / 3}
$$

Application of the thickness-modulus ratio concepts is particularly essential when the Do-nou encapsulated confinement system is applied in multiple layers due to the significant increase in stiffness. The integral part of the results applied in the development of the pavement structural configurations presented in the Design Catalogues summarized in [6].

\section{Structural concepts adopted}

A QM (Quasi-Mechanistic) approach is applied in deriving structural layer thickness equations used in developing Catalogues for Standard Pavement Structure Type for WECS do-nou (soilbag) pavement foundations. The range of the ultimate tensile strength, $T=T_{\text {ult. }}$ and radial (secant) stiffness at $2 \%$ strain, $J_{@ 2 \%}$, of the do-nou (soilbag) fabrics considered was:

\section{口 $6 \leq T_{\text {ult. }} \leq 20 \mathrm{kN} / \mathrm{m}$.}

and for ultimate tensile strength, $T=T_{u l t}$. and within the range indicated below for secant stiffness at $2 \%$ strain, $J_{@ 2 \%}$,

\section{$\square \quad 57 \leq T_{\text {ult. }} \leq 153 \mathrm{kN} / \mathrm{m}$.}

The standard pavement structures developed and the applicable traffic and subgrade classes are presented in the Design Catalogues provided in the charts format in Section 5.7 and Section 5.8 of [6]. Basically, the design for the applicable class of soil and traffic is discreetly presented in a single chart. Brief comments on the peculiarities, advantages, and disadvantages of each type of pavement structural type are provided accordingly [7]. The pavement materials required for use in each chart have been indicated and referenced to the Material Specification Charts, which include a summary of construction procedures provided under Section 5.13 of Chapter 5 of the [8].

\section{E. Methodology for developing standard pavement strucures}

The methodology of developing the standard pavement structures is summarized as follows: i) the subgrade resilient modulus (stiffness) is determined from in-situ mechanical and/or geophysical tests; ii) based on the magnitude of the subgrade stiffness, the required number of do-nou layers is determined from Table V and/or computed using Equation (33) and counter-checked employing Equation (42); alternatively, the nomograph presented in Figure 21 can also be adopted; iii) the bearing capacity and elastic modulus (stiffness) of the natural do-nou fill material is determined from the tables provided in Appendix A4 of [6]; iv) the data and information from 1) and 2) above is then applied to derive the appropriate composite do-nou foundation layer stiffness from Table A4-10 
in Appendix A4.5 of [6]; v) the appropriate composite do-nou foundation layer thickness is determined from the Tables provided in [6]; vi) by considering the standard overlying thickness of the gravel wearing and base courses as: $t_{G W C}=t_{B C}=125 \mathrm{~mm}$, the full-depth pavement and discrete layer thicknesses are determined; vii) gravel loss prediction for the unpaved roads is undertaken by adopting Equations (46); and viii) selection of the most appropriate standard pavement structural configuration can now be made from the Catalogue Design Charts provided in [6]

\section{F. Methodology for developing standard pavement strucures 1) Gravel loss prediction}

Climate has a fundamental influence on road materials and performance particularly for unpaved (gravel wearing course) roads. In this regard therefore, the gravel loss prediction model considers this diversity in terms of intensity of precipitation and gradients. It is therefore prudent to consider, in general, two zones consisting of "wet" and "dry" defined in [9].

In developing the design catalogues for gravel wearing surfaces, gravel loss prediction is performed for the unpaved roads based on model Equation (46a), which should distinctly be in consideration of two (dry and wet) zones.

Pending further modification, the recommended gravel loss model is defined in Equation (46a) The gravel loss, $G_{L}$ model, developed by TRRL based on R\&D carried out in Kenya, is:

$$
G_{L}=f\left(\frac{T_{A}^{2}}{T_{A}^{2}+50}\right)\left[4.2+0.092 T_{A}+3.50 R_{L}^{2}+1.88 G_{R}\right] f_{c m}
$$

where,

$G_{L}$ : Gravel loss in mm; $f:$ Constant depending on type of gravel; for Kenyan gravel; $f=1.29$ for lateritic gravel; $f=1.51$ for quartztic gravel; $f=0.96$ for volcanic gravel; and $f=1.38$ for coral gravel; $T_{A}$ : Annual traffic in both directions measured in thousands of vehicles; $R_{L}$ : Annual average rainfall in measured in metres; $G_{R}$ : Gradient (rise and fall) expressed in percentage of $\mathrm{m} / \mathrm{km}$; $f_{c m}$ : Correction factor correlating to actual measurements defined in Equation (46b).

$$
f_{c m}=0.14977 t_{p c}^{2}+0.21884 t_{p c}+0.009978 \text { (46b) }
$$

where, $t_{p c}=$ elapsed post-construction time or regravelling intervening periods.

\section{2) Gravel Wearing Course (GWC) thickness design}

The required gravel wearing course thickness shall constitute of the structural, $T_{F D \text {,str. }}$ [Equations (47)] and gravel loss, $G_{L}$ portions, yielding the total gravel thickness [10], $T_{F D, t o t}$, as defined in Equation (48).

Essentially, the GWC thickness shall be derived as follows.

(i) Determine the minimum structural thickness necessary to avoid excessive compressive strain in the subgrade [11], $T_{F D, s t r}$. from the Catalogue Design Charts or by applying Equation (47).

(ii) Determine the extra thickness needed to compensate for the gravel loss, $G_{L}$, during the design life or period between regravelling from model Equation (46a).

(iii) Determine the total gravel thickness required by addition of the above two thicknesses [11] as depicted in Equation (48).

$$
\begin{array}{r}
T_{F D, S t r .}^{G W C}=\left[924.66 \ln \left(T_{C E S A}\right)+3624.2\right] M_{R, S G}^{-\left(0.6803 T_{C E S A}^{0.0322}\right)} \times \\
f_{S t r, D L} \times f_{E_{0, G W C}}
\end{array}
$$

where, $T_{C E S A}$ is the cumulative equivalent single axles, $f_{s t r, D L}$ is the structural thickness ratio factor defined in Equation (47b). The $f_{s t r, D L}$ factor is derived from do-nou layer thickness and the factored elastic modulus of the donou fill, $E_{0 f, D f}$ and $f_{E_{0, G W C}}$ is the elastic modulus (stiffness) factor defined in Equation (47c). Fundamentally, the $f_{E_{0, G W C}}$ factor represents/describes the quality of geomaterials used for the GWC (gravel wearing course). Note that a ramification reduction factor, $R_{f_{E M}}=0.833\left(F_{S}=1.2\right)$ is applied on both the elastic modulus for the do-nou foundation and gravel wearing course geomaterials.

$$
\begin{gathered}
f_{s t r, D L}=2.7022 E_{0 f, D L}^{-0.276} \\
f_{E_{0, G W C}}=3.5185 E_{0 f, G W C}^{-0.276} \\
T_{F D, \text { tot. }}=T_{F D, S t r .}^{G W C}+G_{L}
\end{gathered}
$$

G. Full-Depth and base course thickness design for LVSRS

The models adopted for determining and/or counterchecking the appropriate full-depth, $T_{F D}^{O p t}$. and base course, $t_{B C}^{O p t .}$ structural thicknesses as functions of subgrade stiffness (resilient modulus), cumulative traffic loading and elastic modulus of the do-nou fill geomaterial are provided in Equations (49) and (50), respectively. The thickness determined from these models and the thickness-modulus ratio models defined in Equations (43) (45) are employed in generating the pavement structural configurations presented in the Design Catalogues in [6].

$$
\begin{array}{r}
T_{F D, \text { Seal }}^{\text {Opt. }}= \\
\alpha_{M_{R, N S G}} \ln \left[2786.4 M_{R, \mathrm{~N} S G}^{(-0.557)} N_{A, D L}^{\left(0.0535 \ln \left(M_{R, \mathrm{~N} S G}\right)-0.0591\right)} \times\right. \\
\left.f_{\text {str,DL }} \times f_{E_{0 f, B C}}\right]-\beta_{M_{R, N S G}}
\end{array}
$$

where, $\alpha_{M_{R, N S G}}$ and $\beta_{M_{R, N S G}}$ are factors that account for thickness-modulus ratios of low volume sealed roads defined in Equation (49b) and Equation (49c), $M_{R, N S G}$ is the resilient modulus of the natural (native) subgrade prior to improvement, $N_{A, D L}$ is the cumulative traffic loading defined in terms of ESALs (equivalent single axles) and $f_{s t r, D L}$ is the structural thickness ratio factor of the do-nou fill geomaterial. The $f_{s t r, D L}$ factor is derived from Equation (49b), whilst $f_{E_{0 f, B C}}$ is the factored elastic modulus (stiffness) factor defined in Equation (49d). Fundamentally, the $f_{E_{0} f B C}$ factor represents/describes the quality of geomaterials used for the $\mathrm{BC}$ (base course). Note that a ramification reduction factor, $R_{f_{E M}}=0.833\left(F_{S}=1.2\right)$ is applied on the elastic modulus for the base course.

$$
\begin{gathered}
\alpha_{M_{R, N S G}}=35776 M_{R f, N S G}^{-1.193} \\
\beta_{M_{R, N S G}}=322112 M_{R f, N S G}^{-1.343} \\
f_{E_{0 f, B C}}=3.7045 E_{0 f, B C}^{-0.276}
\end{gathered}
$$

The optimum base course layer thickness, $t_{B C}^{O p t}$ is, on the other hand, determined from the model defined in Equation (50). 


$$
\begin{aligned}
& t_{B C}^{O p t .}=2.7\left[M_{R, S G}^{-0.336} \times T_{F D}^{O p t .}\right]^{0.9426} \times\left\{\left[1.3685 \times 10^{-5} T_{F D}^{2}-\right.\right. \\
& \left.\left.0.008 T_{F D}+6.6505\right] \times M_{R, S G}^{-\left[-3.3 \times 10^{-8} T_{F D}^{2}+2 \times 10^{-5} T_{F D+0.3409}\right]}\right\}^{-1}
\end{aligned}
$$

\section{POSSIBLE FUNCTIONS AND ATTESTED APPLICATIONS}

The Possible functions and attested applications are introduced [5]. The possible functions, depending on the quality, type and properties of the do-nou fill geomaterials, may include: i) Separation: the prevention from intermixing of adjacent issimilar soils and or materials; ii) Filtration: the retaining of soil or other particles subject to hydrodynamic forces while allowing the passage of fluids into or through the soilbag; iii) Drainage: the collecting and transmitting of precipitation, ground water and or other liquids or gases along the plane of the soilbag; iv) Reinforcement: the use of the properties of a soilbag to improve the mechanical properties of soil or other construction materials; v) Barrier: the prevention or reduction of the movement of any fluid through a construction by the use of a soilbag barrier; vi) Protection: the use of a soilbag material as a localised stress reduction or dissipation layer to prevent or reduce damage to a given surface, material or layer; vii) Surface erosion control: the use of a soilbag to prevent soil or other particle movements on the surface of a slope; viii) Stabilization: improvement of the mechanical behaviour of an unbound granular material by including one or more soilbag layers such that deformation under applied loads is reduced by minimizing movement of the unbound granular material.

Attested applications of the WECS include: i) reinforcement of road subgrades/foundations; ii) reinforcement of building foundations (see Figure 1-5); iii) reinforcement of railway foundations; iv) construction of retaining walls; v) construction of embankments; vi) piling; vii) reduction in settlement; and viii) reduction in vibrations/noise.

In Kenya, WECS was initially introduced as a labour based Do-nou (soilbags) technology. Below are the advantages of the WECS including Do-nou that make it unique as a useful technology [2]: i) does not involve use of any cement or chemical agents thus it is environment-friendly; ii) no special construction equipment is needed; iii) the materials inside soil bags may be any construction wastes such as concrete, asphalt, tire and tile wastes as well as granular remains after garbage treatment; iv) thus soil bags can also contribute to the recycle of waste materials; $v$ ) the soil bag itself has a high compressive strength; vi) it has an effect of reducing traffic- or machineinduced vibration; implicitly/retrospectively, it may also have the inherent propensity to reduce earthquake vibration; vii) it has an effect of preventing heave if course granular are filled in the bags; viii) as demonstrated in Figure waterlogged soft ground may also be effectively reinforced.

A typical cross section for WECS (do-nou) rut improvement is shown in Figure 22.

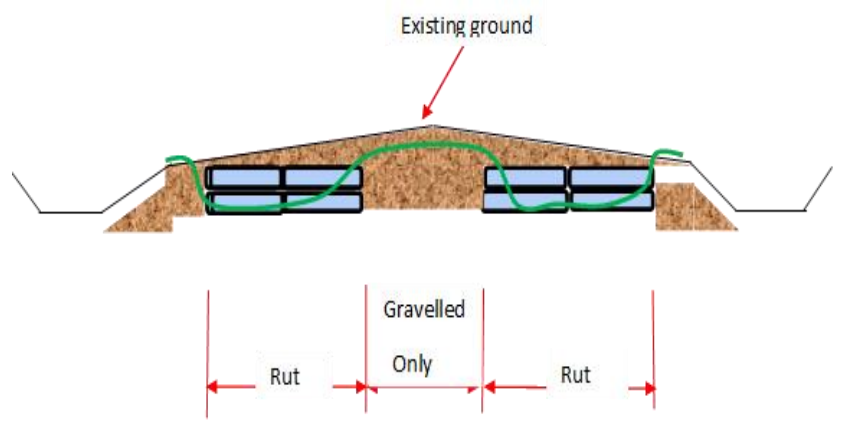

Fig. 22. Typical WECS Do-nou cross sections for improvement of ruts.

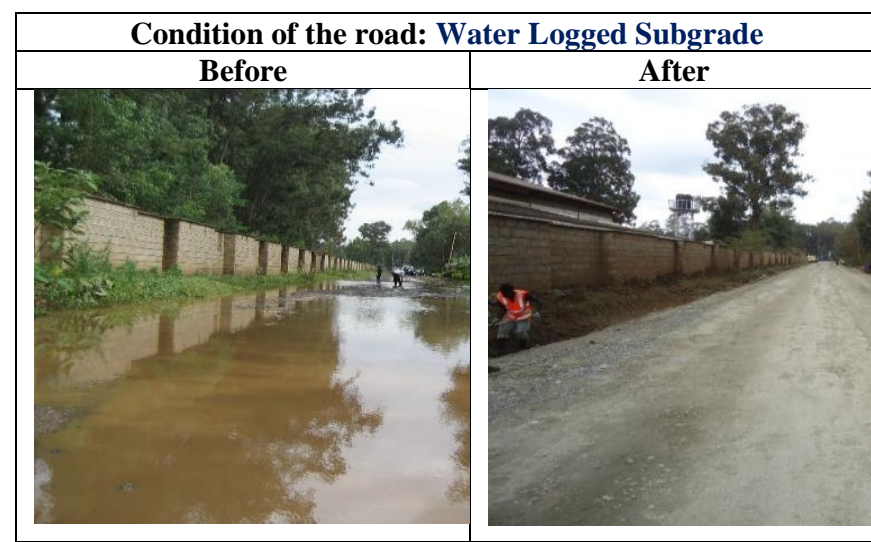

Condition of the road: Problematic (Expansive) Black Cotton Soil Subgrade

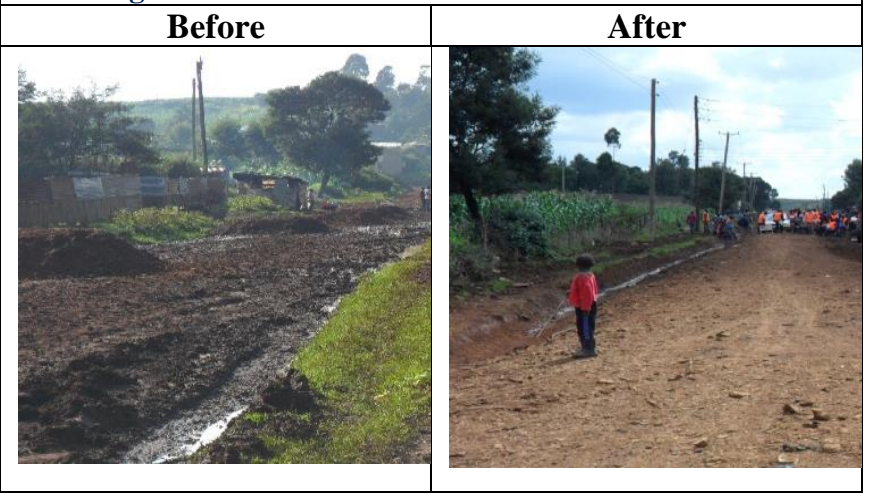

Fig. 23. Application of the WECS soilbag (do-nou) technology for the construction of the roads constructed within: a) water logged sections; and b) problematic(expansive) black cotton soils

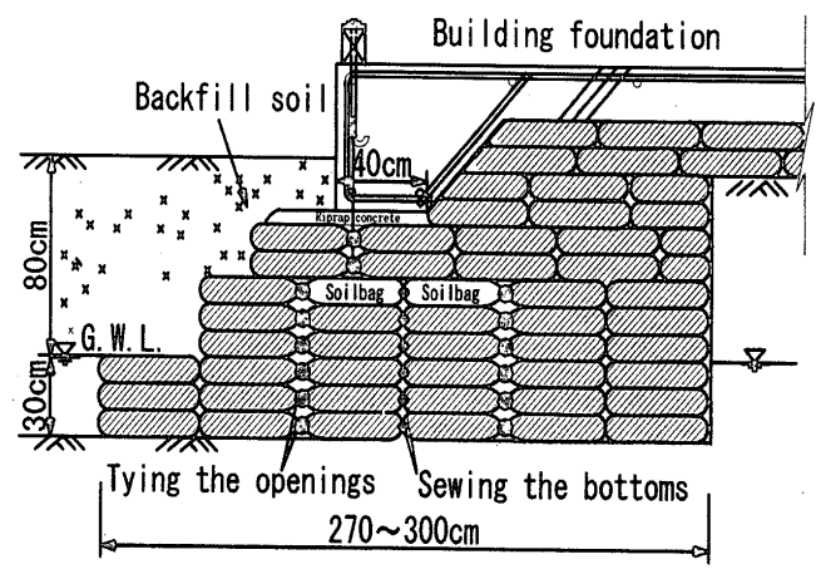

Fig. 24. Application of the Do-nou WECS technology for improvement of building foundations (Matsuoka and Liu, 2003). 


\section{CONCLUSIONS}

In this paper, it has been demonstrated that the proposed analytical models equipped with a variety of application modules are unique functional and effectively applicable for the design of wholly encapsulated confinement systems (WECS) comprising of polymeric soilbags (do-nou). Application of the proposed models has also been practically manifested through graphical examples for the characterization of the influence factors and material properties as well generation of imperative design parameters. The design characteristic curves and parametric values generated based on the application of these models distinctly confirm the validity, lucidity and rationality of the proposed analytical models.

\section{ACKNOWLEDGMENT}

The author wishes to acknowledge, with utmost gratitude, the Materials Testing \& Research Department, Ministry of Transport, Infrastructure, Housing \& Urban Development in Kenya, the International Labour Organization (ILO), the Community Road Empowerment (CORE), the Japan International Cooperation Agency as well as the Research Teams of Kensetsu Kaihatsu Engineering Consultants Limited and the Kenya Geotechnical Society (KGS) for their relentless efforts in providing the due assistance that culminated in the successful compilation of this paper.

\section{REFERENCES}

[1] Matsuoka H. and Liu, S., New Earth Reinforcement Method by Soilbags ("Donow")", Soils and Foundations, Japanese Geotechnical Society, Vol 43(6), pp.173-188, 2003

[2] Yoshinori Fukubayashi and Makoto Kimura, Improvement of Rural Access Roads in Developing Countries with Initiative for Self-reliance of Communities, June 2013

[3] Matsuoka H. and Liu, S. A New Earth Reinforcement Method using Soilbags, London, Taylor \& Francis Group, 2006

[4] Materials Testing and Research Department (MTRD), Ministry of Transport, Infrastructure, Housing and Urban Development: "Do-nou Technology Evaluation Report No. 1314 of April, 2018

[5] US-FHWA-NHI (United States Federal Highway Authority-National Highway Institute), Geosynthetic Design Guidelines Reference Manual, FHWA-NHI-07-092: August, 2008.

[6] Materials Testing and Research Department (MTRD), Ministry of Transport, Infrastructure, Housing and Urban Development: "PDG 4: Daft Interim Guideline for Design and Structural Improvement of Low Volume Roads Using Do-nou Technology”, March, 2018.

[7] J .N. Mukabi, "Profound methodology for prediction and evaluation of performance of GRE walls for road embankment and bridge abutments", Proceedings of the XXVth World Road Congress, Seoul, South Korea, November 2015, CD-Rom.

[8] Ministry of Transport, Infrastructure, Housing and Urban Development, PDG 1: Pavement Design Guideline for Low Volume Sealed Roads; April, 2017.

[9] Kenya Road Design Manual Part III. Materials and Pavement Design for new roads, Roads Department Ministry of Roads and Public works, 1987

[10] J.N. Mukabi, "Proposed unique quasi-mechanistic models for advanced design of GMSE and GRS retaining wall geo-structures", Proceedings of the 3rd World Congress on Civil, Structural and Environmental Engineering, Budapest, Hungary, 2018.

[11] J.N. Mukabi, "Inimitable Approach to design of foundations for GMSE and GRS retaining walls based on a case example", Proceedings of the 3rd World Congress on Civil, Structural and Environmental Engineering, Budapest, Hungary, 2018. 